\title{
Transcriptomic alterations in the heart of non-obese type 2 diabetic Goto-Kakizaki rats
}

\author{
Márta Sárközy ${ }^{1}$, Gergő Szűcs ${ }^{1,2}$, Veronika Fekete ${ }^{1}$, Márton Pipicz , Katalin Éder ${ }^{3}$, Renáta Gáspár ${ }^{1}$, Andrea Sója ${ }^{1}$, \\ Judit Pipis ${ }^{4}$, Péter Ferdinandy ${ }^{4,5}$, Csaba Csonka $^{1}$ and Tamás Csont $^{1^{*}}$
}

\begin{abstract}
Background: There is a spectacular rise in the global prevalence of type 2 diabetes mellitus (T2DM) due to the worldwide obesity epidemic. However, a significant proportion of T2DM patients are non-obese and they also have an increased risk of cardiovascular diseases. As the Goto-Kakizaki (GK) rat is a well-known model of non-obese T2DM, the goal of this study was to investigate the effect of non-obese T2DM on cardiac alterations of the transcriptome in GK rats.
\end{abstract}

Methods: Fasting blood glucose, serum insulin and cholesterol levels were measured at 7, 11, and 15 weeks of age in male GK and control rats. Oral glucose tolerance test and pancreatic insulin level measurements were performed at 11 weeks of age. At week 15, total RNA was isolated from the myocardium and assayed by rat oligonucleotide microarray for 41,012 genes, and then expression of selected genes was confirmed by qRT-PCR. Gene ontology and protein-protein network analyses were performed to demonstrate potentially characteristic gene alterations and key genes in non-obese T2DM.

Results: Fasting blood glucose, serum insulin and cholesterol levels were significantly increased, glucose tolerance and insulin sensitivity were significantly impaired in GK rats as compared to controls. In hearts of GK rats, 204 genes showed significant up-regulation and 303 genes showed down-regulation as compared to controls according to microarray analysis. Genes with significantly altered expression in the heart due to non-obese T2DM includes functional clusters of metabolism (e.g. Cyp2e1, Akr1b10), signal transduction (e.g. Dpp4, Stat3), receptors and ion channels (e.g. Sln, Chrng), membrane and structural proteins (e.g. Tnni1, Mylk2, Col8a1, Adam33), cell growth and differentiation (e.g. Gpc3, Jund), immune response (e.g. C3, C4a), and others (e.g. Lrp8, Msln, Klkc1, Epn3). Gene ontology analysis revealed several significantly enriched functional inter-relationships between genes influenced by non-obese T2DM. Protein-protein interaction analysis demonstrated that Stat is a potential key gene influenced by non-obese T2DM.

Conclusions: Non-obese T2DM alters cardiac gene expression profile. The altered genes may be involved in the development of cardiac pathologies and could be potential therapeutic targets in non-obese T2DM.

Keywords: Spontaneous diabetes mellitus, Inherited diabetes mellitus, Non-obese type 2 diabetes mellitus, Myocardium, DNA microarray, GO, String, Insulin resistance

\section{Background}

Diabetes mellitus is a heterogeneous chronic metabolic disorder characterized by hyperglycemia as a common feature resulting from impaired insulin secretion, insulin resistance, or both [1]. In 2014, the global prevalence of

\footnotetext{
*Correspondence: csont.tamas@med.u-szeged.hu

${ }^{1}$ Department of Biochemistry, Faculty of Medicine, University of Szeged, Dóm tér 9, Szeged 6720, Hungary

Full list of author information is available at the end of the article
}

diabetes mellitus (DM) was estimated to be $9 \%$ among adults according to WHO data [2]. The total number of people suffering from DM is projected to almost triple from 190 million to 552 million by 2030 [3, 4]. T2DM accounts for more than $90 \%$ of all diabetes cases and its incidence is continuously rising worldwide $[1,5,6]$. The major cause for this phenomenon is the so-called obesity epidemic due to physical inactivity and increased consumption of energy-rich food [7]. Nevertheless, it is often 
neglected that around $20 \%$ of T2DM patients are nonobese in Europe and Asia [7-10]. The non-obese T2DM phenotype is characterized by a more pronounced reduction in insulin secretion and less severe insulin resistance as compared to obese T2DM patients [7]. The risk of T2DM in non-obese individuals is considered to be mostly influenced by polygenic inheritance and prenatal environment [7].

It is well known that diabetic patients have an increased risk of developing a number of co-morbidities including cardiovascular diseases (CVD). It has been reported that T2DM patients have a two to fourfold increased risk of CVD in general $[7,11,12]$. Obesity is recognized as an independent risk factor for both T2DM and CVD $[7,13]$. Interestingly, it has been reported that non-obese T2DM patients also have a high risk of CVD similarly to that of obese T2DM patients $[7,11,14]$. Indeed, CVD are estimated to be responsible for more than $50 \%$ of deaths among T2DM population [15].

One of the major pathologies of the aforementioned CVD is diabetic cardiomyopathy (DCM) $[15,16]$. DCM is defined as left ventricular (LV) diastolic and/or systolic dysfunction with hypertrophy and fibrosis in the absence of preceding hypertension, coronary artery disease and valvular or congenital heart disease [15-17]. Although DCM is a distinct clinical entity, it is also a part of the diabetic atherosclerosis process [18]. DCM might be independent of the coexistence of arterial hypertension, coronary artery disease or other macrovascular complications [18]. DCM is characterized by the development of myocardial damage, reactive hypertrophy and fibrosis, structural and functional changes of the small coronary vessels, and cardiac autonomic neuropathy [18]. These alterations make the diabetic heart more susceptible to ischemia and subsequent remodelling [18-20].

We have previously shown that cardiac gene expression pattern is significantly altered in obese ZDF rats, a model of T2DM and metabolic syndrome [21], and in streptozotocin-induced T1DM rats [22] at the transcript level. The effect of non-obese T2DM on gene expression pattern in various tissue types has been investigated in a few studies. Pancreatic islets [23, 24], liver [25], skeletal muscle [26], adipose tissue [27], hippocampus and prefrontal cortex [28] obtained from the well-known non-obese T2DM model Goto-Kakizaki (GK) rat showed altered gene expression pattern as compared to controls. Surprisingly, whole transcriptomic analysis in the heart of GK rats has not been performed previously. Therefore, in the present study, our aim was to investigate the effect of non-obese T2DM on cardiac alterations of the transcriptome in GK rats.

\section{Methods}

\section{Ethics approval}

This investigation conforms to the National Institutes of Health Guide for the Care and Use of Laboratory Animals (NIH Pub. No. 85-23, Revised 1996) and was approved by the Animal Research Ethics Committee of the University of Szeged.

\section{Animal model of non-obese T2DM}

Male Goto-Kakizaki rats and their age-matched male Wistar controls were obtained from Charles River Laboratories at the age of 6 weeks and were housed at $22 \pm 2{ }^{\circ} \mathrm{C}$ with a $12: 12$-h light-dark cycle. The rats received standard rat chow and water ad libitum for 9 weeks after their arrival. The GK rat is a recognized model of inherited type 2 diabetes mellitus [29]. This spontaneously diabetic rat strain was developed by selective breading of Wistar rats with the highest normal blood glucose levels in response to oral glucose tolerance test [30,31]. GK rats develop a non-obese and mild hyperglycemic phenotype at week 4-5 accompanied by a metabolic state of glucose intolerance and later peripheral insulin resistance $[29,32]$ which develops to a hyperglycemic insulin-deficient state with aging [29, 32-34]. The metabolic features manifested in this animal model are in many ways similar to the pathogenesis of inherited spontaneous T2DM in humans [29, 32]. However, hyperglycemia and glucose intolerance developed in GK rats are not associated with the development of obesity or hypertension [1]. The adult GK rat of T2DM has been shown to develop cardiovascular complications including left ventricular hypertrophy, fibrosis, as well as diastolic and/or systolic dysfunction $[1,20,35,36]$. Therefore, the GK rat is an applicable model for investigation of the consequences of non-obese T2DM in the heart.

\section{Experimental setup}

Body weight, serum glucose, insulin, cholesterol levels and homeostasis model assessment-estimated insulin resistance (HOMA-IR) were determined at 7, 11 and 15 weeks of age in order to monitor the basic parameters of glucose and lipid metabolism and insulin resistance in GK and control rats (Figs. 1, 2, 3). Oral glucose tolerance test (OGTT) was performed at week 15 to further characterize glucose homeostasis of GK and control rats (Fig. 2). At 15 weeks of age, rats were anaesthetized using pentobarbital sodium (Euthasol, $50 \mathrm{mg} / \mathrm{kg}$, Produlab Pharma b.v., Raamsdonksveer, The Netherlands). Hearts and pancreata were isolated, and then hearts were perfused according to Langendorff as described earlier [21, 37]. After $5 \mathrm{~min}$ perfusion ventricular tissue was frozen and stored at $-80{ }^{\circ} \mathrm{C}$ until gene expression analysis by DNA microarray and qRT-PCR techniques. 

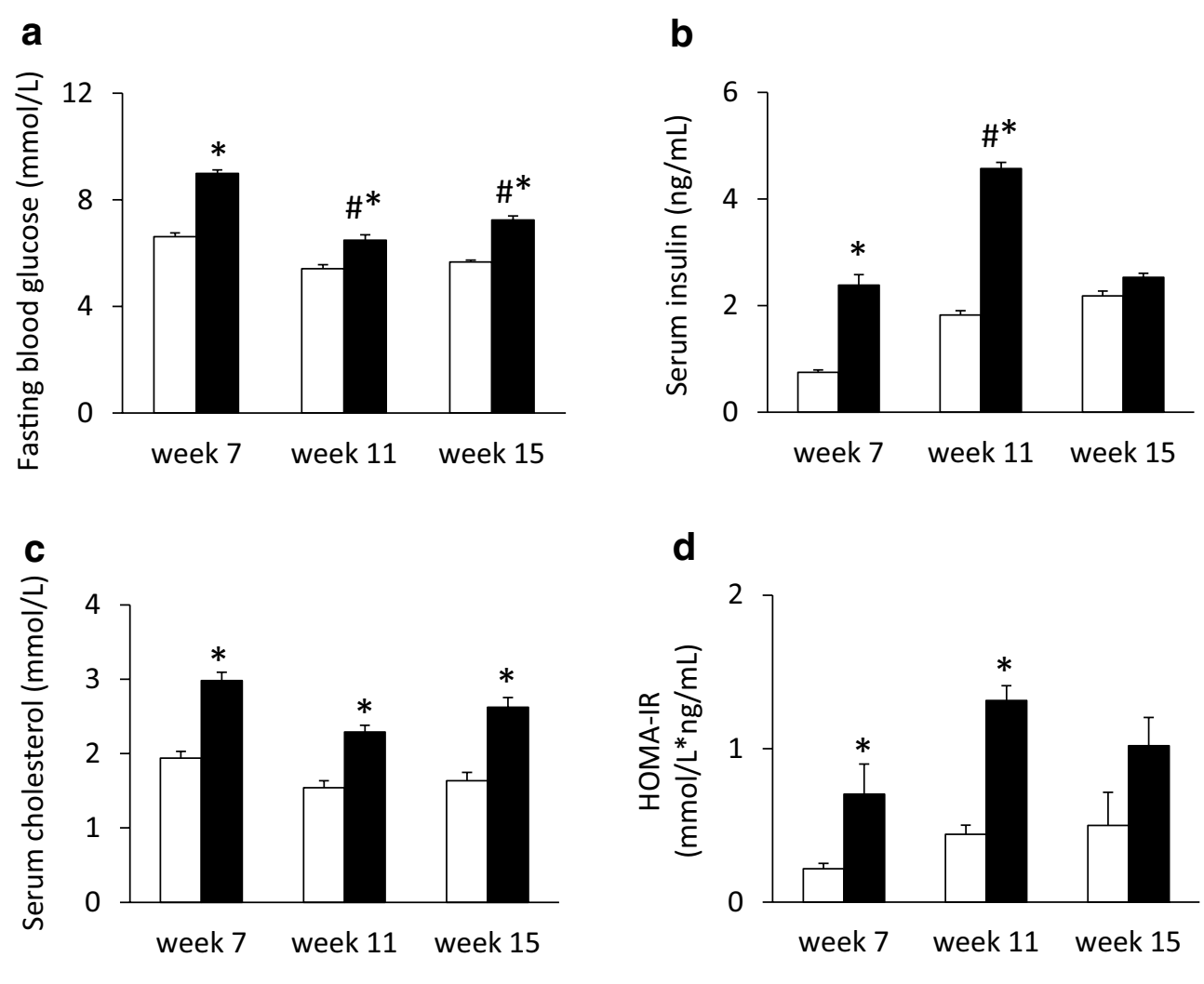

Fig. 1 Fasting blood glucose, serum insulin and cholesterol levels. Fasting blood glucose (a), serum insulin (b) and cholesterol (c) levels as well as HOMA-IR index (d) at weeks 7, 11 and 15 in both control and GK rats. Values are mean $\pm S E M, n=7-9,{ }^{*} p<0.05$ vs. control within the same time point, ${ }^{\#} p<0.05$ vs. week 7 values

\section{Serum glucose level measurements and OGTT}

As described previously, rats were fasted overnight $(12 \mathrm{~h})$ prior to serum glucose level measurements and OGTTs (weeks 7, 11 and 15) to verify the development of hyperglycemia and glucose-intolerance as diagnostic criteria of diabetes mellitus [21, 22, 36]. Blood samples were collected from the saphenous vein. Blood glucose levels were measured using AccuCheck blood glucose monitoring systems (Roche Diagnostics Corporation, USA, Indianapolis) [21, 22, 38]. In case of OGTT, after the measurement of baseline glucose concentrations, $1.5 \mathrm{~g} /$ $\mathrm{kg}$ body weight glucose was administered per os via gavage and blood glucose levels were checked 30, 60 and $120 \mathrm{~min}$ later $[21,22,38]$. Area under the curve values for OGTT was also calculated.

\section{Measurement of serum and pancreatic insulin levels}

Serum and pancreatic insulin levels were measured by an enzyme-linked immunosorbent assay (Mercodia, Ultrasensitive Rat Insulin ELISA) as described previously [21, 22, 38]. Blood samples were collected from the saphenous vein at weeks 7,11 and 15 . At week 15, during OGTT blood was collected at 0,30 and $120 \mathrm{~min}$ for serum insulin level measurements. Blood samples were centrifuged (4500 rpm for $10 \mathrm{~min}$ at $4{ }^{\circ} \mathrm{C}$ ) and kept at $-20{ }^{\circ} \mathrm{C}$ until the assay was performed. At week 15, pancreata were removed, trimmed free of adipose tissue and weighed. Pancreata were homogenized in $6 \mathrm{~mL}$ cold acidified-ethanol $(0.7 \mathrm{M}$ $\mathrm{HCl}$ : ethanol, 1:3 v/v) with an Ultraturrax homogenizer and were kept at $4{ }^{\circ} \mathrm{C}$ for $24 \mathrm{~h}$. Then pancreas homogenates were centrifuged $(900 \mathrm{~g}$ for $15 \mathrm{~min}$ at $4{ }^{\circ} \mathrm{C}$ ), and the supernatants were stored at $4{ }^{\circ} \mathrm{C}$. The pellet was extracted again with $3 \mathrm{~mL}$ acidified ethanol for $24 \mathrm{~h}$ at $4{ }^{\circ} \mathrm{C}$. The supernatant obtained after centrifugation was pooled with the previous one and kept at $-20{ }^{\circ} \mathrm{C}$ until assayed. Insulin ELISA was carried out according to the instructions of the manufacturer from either sera or homogenized pancreatic tissue samples of GK and control rats. 

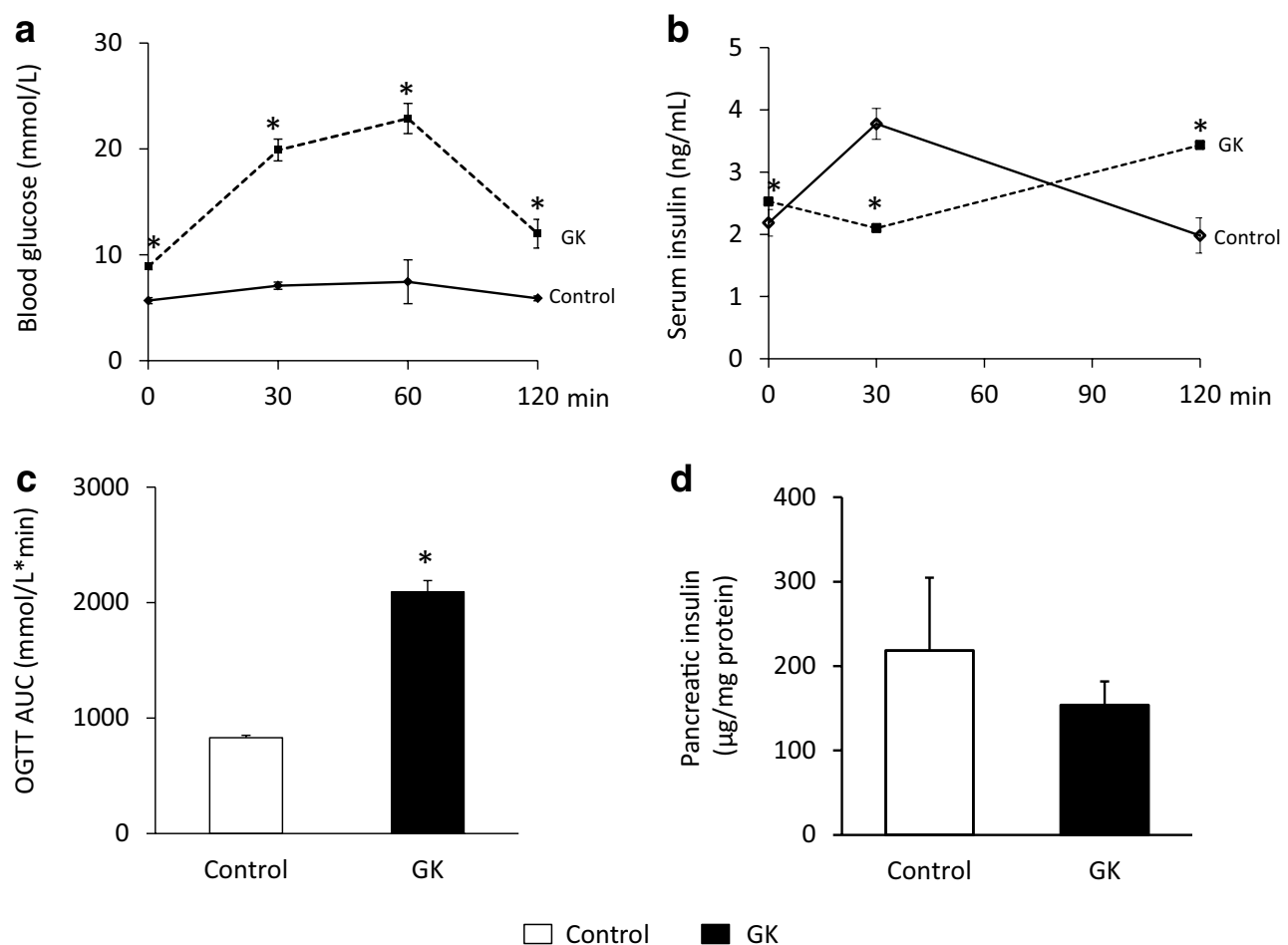

Fig. 2 Blood glucose and insulin levels during OGTT and pancreatic insulin content. Blood glucose (a) and serum insulin (b) levels during OGTT, OGTT AUC (c) and pancreatic insulin (d) content at week 15 in both control and GK rats. Solid line control; dashed line GK. Values are mean \pm SEM, $n=7-9,{ }^{*} p<0.05$
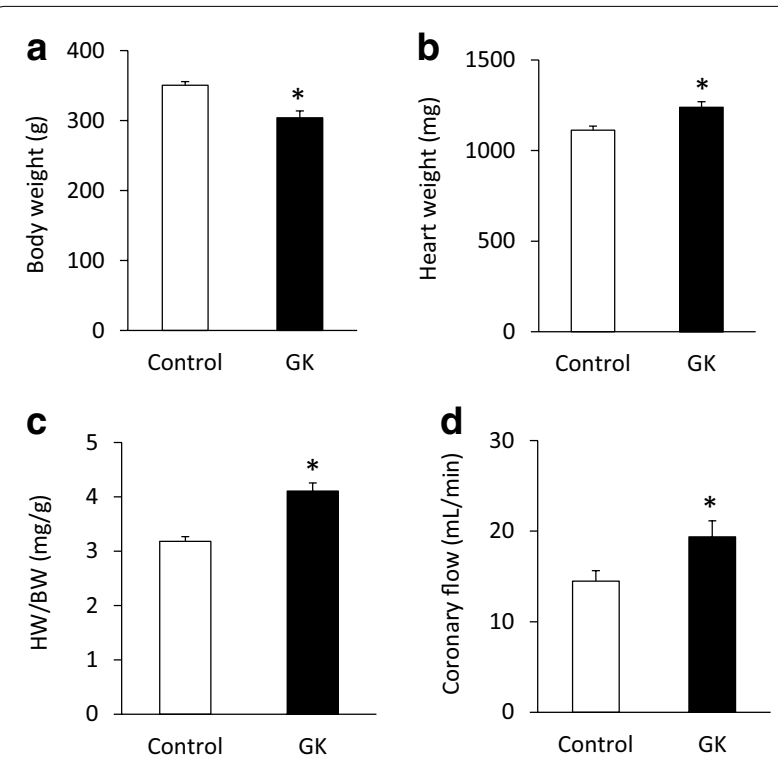

Fig. 3 Body weight, heart weight and coronary flow. Body weight $(\mathbf{a})$, heart weight $(\mathbf{b})$, heart weight to body weight ratio (c) and coronary flow (d) at week 15 in both control and GK rats. Values are mean \pm SEM, $n=7-9,{ }^{*} p<0.05$

\section{HOMA-IR index}

To estimate insulin resistance in GK or control rats the widely used HOMA-IR index was calculated [21,39] by multiplying fasting serum insulin $(\mu \mathrm{g} / \mathrm{mL})$ with fasting blood glucose $(\mathrm{mmol} / \mathrm{L})$, then dividing by the constant 22.5 , i.e. HOMA-IR $=$ (fasting serum insulin concentration $\times$ fasting blood glucose concentration)/22.5.

\section{Measurement of serum cholesterol levels}

In order to follow up the development of hypercholesterolemia which is a risk factor of cardiovascular diseases, serum cholesterol levels were measured at weeks 7,11 and 15 using a test kit (Diagnosticum Zrt., Budapest, Hungary) as described previously [21, 40,41].

\section{RNA preparation and DNA microarray analysis}

Total RNA was isolated from heart samples with Qiagen miRNeasy Mini Kit according to the manufacturer's protocol (Qiagen, Hilden, Germany) as described previously [22]. On-column DNase digestion was carried out with the RNase-Free DNase Set (Qiagen GmbH). RNA concentration was measured by NanoDrop 1000 
Spectrophotometer (Thermo Fisher Scientific Inc., Waltham, MA, USA) and RNA integrity was determined by an Agilent 2100 Bioanalyzer System (Agilent Technologies Inc., Santa Clara, CA, USA). Samples with an RNA integrity number (RIN) above 8.0 were used for further analysis. RNA was stored at $-80^{\circ} \mathrm{C}$ until use.

Total RNA (1000 ng) was labelled and amplified using the QuickAmp Labelling Kit according to the instructions of the manufacturer. Labelled RNA was purified and hybridized to Agilent Whole Rat Genome $4 \times 44 \mathrm{~K}$ array slides, according to the manufacturer's protocol. After washing, array scanning and feature extraction was performed with default scenario by Agilent DNA Microarray Scanner and Feature Extraction Software 9.5.

\section{Messenger RNA (mRNA) expression profiling by qRT-PCR}

In order to validate gene expression changes obtained by DNA microarray, qRT-PCR was performed with gene-specific primers. Total RNA $(1 \mu \mathrm{g})$ was reverse transcribed using High-Capacity cDNA Reverse Transcription Kit (Thermo Fisher Scientific, Waltham, MA US). Quantitative RT-PCR was performed using TaqMan Array 96 Well Fast Plate $3 \times 32$ (Thermo Fisher Scientific, Waltham, MA US) according to the manufacturer's instructions on a 7900HT Fast Real-Time PCR System. Each well of the TaqMan Array Plate contained $5 \mu \mathrm{L}$ of Taqman Fast Universal Master Mix (2X) no AmpErase ${ }^{\circledR}$ UNG, $1 \mu \mathrm{L}$ cDNA $(50 \mathrm{ng} / \mu \mathrm{L})$ and $4 \mu \mathrm{L}$ distilled water in a final reaction volume of $10 \mu \mathrm{L}$ per well. Then qPCR was performed with the following protocol: 50 cycles of $95^{\circ} \mathrm{C}$ for $15 \mathrm{~s}$ and $60{ }^{\circ} \mathrm{C}$ for $1 \mathrm{~min}$. The fluorescence intensity was detected after each amplification step. Melting temperature analysis was done after each reaction to check the quality of the products. Primers were designed using the online TaqMan ${ }^{\circledR}$ Assays custom plating service of the manufacturer. Relative expression ratios were calculated as normalized ratios to rat glyceraldehyde-3-phosphate dehydrogenase (GAPDH), hypoxanthine phosphoribosyltransferase (HPRT) and ribosomal protein S18 (RPS18) housekeeping genes. A non-template control sample was used for each primer to check primer-dimer formation. Normalized signal levels for each mRNA were calculated using comparative cycle threshold method (delta-delta $\mathrm{Ct}$ method). Fold change refers to $2^{-\Delta \Delta \mathrm{Ct}}$ (in the case of up-regulated genes) and $-\left(1 / 2^{-\Delta \Delta \mathrm{Ct}}\right)$ (in the case of down-regulated genes).

\section{Gene ontology (GO) analysis}

By using DNA microarrays for transcriptional profiling a large number of genes can be analyzed simultaneously $[21,42]$, however, the resulting data do not give direct information about possible biological interaction of the differentially expressed genes. GO analysis is a suitable method for integration genes with pathways and biological interaction networks to detect coordinated changes in functionally related genes [21, 42]. GO analysis was performed using GO pathway analysis using the open access software DAVID bioinformatics system and database (Database for Annotation, Visualization and Integrated Discovery, http://www.david.abcc.ncifcrf.gov website) $[21,42]$. The differentially expressed genes were submitted to DAVID bioinformatics system and database to reveal significantly enriched biological functions/pathways $[21,42]$.

\section{Protein-protein interaction analysis}

Gene expression networks are of great biological interest since co-expressed genes could be (1) controlled by the same transcriptional regulatory program, (2) functionally related, or (3) members of the same pathway or protein complex [43]. In order to further characterize the connections of significantly altered genes obtained by DNA microarray, protein-protein network analysis was performed by STRING10 based on two types of evidence: experimental (protein-protein interaction databases) and text-mining (abstracts of scientific literature). STRING (http://www.string-db.org/), is an online accessible database of known and predicted protein-protein interactions. Protein-protein interactions from STRING 10 were collected for the construction of differential protein interaction network among the genes whose expressions were significantly different in hearts of GK rats. The differently expressed genes were mapped to the String database and then known and predicted associations were scored and integrated. Combined-score $>0.4$ was the threshold. Differently expressed genes were visualized after KMEANS clustering. Finally, interaction network was constructed by integrating these relationships.

\section{Statistical analysis}

Statistical analysis was performed by using Sigmaplot 12.0 for Windows (Systat Software Inc). All values are presented as mean \pm SEM. Repeated measures Two-Way ANOVA was used to determine the effect of T2DM and the age on FBG, serum insulin and cholesterol levels as well as glucose levels during OGTT. After ANOVA, all pairwise multiple comparison procedures with HolmŠ́íák post hoc tests were used as multiple range tests. Two sample $t$ test was used to determine the effect of T2DM on OGTT AUC, pancreatic insulin concentration, body weight, heart weight, heart weight/body weight ratio and coronary flow. $\mathrm{P}<0.05$ was accepted as a statistically significant difference. In the microarray experiments, biological and technical replica tests were carried out to gain raw data for statistical analysis. Altogether 4 individual parallel gene activity comparisons were done 
between the two groups. Both in the microarray and qRTPCR experiments, a two-sample $t$ test was used and the $p$ value was determined to find significant gene expression changes. In the microarray experiments, a corrected $p$ value was determined for each gene to control the false discovery rate using the Benjamini and Hochberg multiple testing correction protocol. Gene expression ratios with $\mathrm{p}$ value of $<0.05$ and $\log _{2}$ ratio of $<-1.00$ or $\log _{2}$ ratio of $>1.00$ ( $\sim 2.0$-fold were considered as repression or overexpression respectively in gene activity.

\section{Results}

\section{Metabolic characterization of non-obese T2DM}

In order to verify the development of T2DM in male GK rats, concentrations of several serum metabolites were measured at weeks 7, 11 and 15 (Fig. 1). GK rats showed a significantly elevated FBG level at all time points as compared to controls (Fig. 1a). Interestingly, blood glucose level in GK rats were significantly lower at week 11 as compared to week 7 or week 15 blood glucose values (Fig. 1a). Parallel with hyperglycemia, serum insulin levels were significantly increased in GK rats compared to Wistar controls at week 7 and more profoundly at week 11 showing the presence of hyperinsulinemia in GK animals (Fig. 1b). However, there was no significant difference between serum insulin levels measured in GK and control rats at week 15, since serum insulin concentration in GK rats significantly decreased by week 15 as compared to insulin level measured at week 11 indicating beta-cell damage in GK rats (Fig. 1b). HOMA-IR was significantly increased at weeks 7 and 11 in GK rats when compared to controls showing insulin resistance in GK animals (Fig. 1d). In contrast, increase of HOMA-IR did not reach the level of statistical significance at week 15 in GK animals (Fig. 1d). Serum cholesterol levels were significantly higher in GK rats as compared to control ones throughout the study duration representing hypercholesterolemia (Fig. 1c). OGTT was performed at week 15 in order to verify the development of impaired glucose tolerance in GK rats. Glucose levels during OGTT were markedly increased in GK rats in every time point of blood glucose measurements (Fig. 2a). Area under the curve (AUC) of blood glucose levels during OGTT was significantly increased in GK rats representing impaired glucose tolerance (Fig. 2c). In addition, serum insulin level in GK rats during OGTT was significantly lower $30 \mathrm{~min}$ after glucose loading and became markedly increased $120 \mathrm{~min}$ after glucose administration indicating impaired insulin secretion (Fig. 2b). Interestingly, pancreatic insulin levels were $25 \%$ lower in GK rats compared to control ones, however, the values were not significantly different between the two groups (Fig. 2d).

\section{Body weight, heart weight and coronary flow}

Body weight was significantly decreased at week 15 in GK rats proving a non-obese phenotype of T2DM in GK rats (Fig. 3a). Heart weight and heart weight to body weight ratio were significantly increased at week 15 in GK rats suggesting the development of cardiac hypertrophy in response to chronic T2DM (Fig. 3b, c). Interestingly, coronary flow was significantly increased at week 15 in GK rats as compared to control hearts (Fig. 3d).

\section{Gene expression profile and qRT-PCR}

Among the 41,012 genes surveyed (Additional file 1: Table S1), 507 genes whose expression was $>\sim 2.0$-fold up- or down-regulated in hearts of GK rats relative to levels of control rats showed significant change in expression. According to our results, 204 genes showed upregulation (Additional file 2: Table S2) and 303 genes showed down-regulation in hearts of GK rats (Additional file 2: Table S3). Moreover, 138 genes showed more than threefold change of expression in hearts of GK rats as compared to the levels of control rats. Among these 138 genes, 50 genes were significantly up-regulated (Table 1) and 88 genes were significantly down-regulated (Table 2) in GK rat hearts. The expression change of selected 28 genes was validated by qRT-PCR (Table 3), 19 of these 28 genes have been confirmed by qRT-PCR (Table 3 ).

\section{Gene ontology analysis}

In order to further determine the biological significance and functional classification of differentially expressed genes due to non-obese T2DM, GO analysis was performed (Table 4) [21]. GO analysis is suitable for identifying significantly enriched GO terms related to multiple genes and for discovering enriched functionally related gene groups. A single gene can belong to different categories. Out of the 507 genes significantly altered by nonobese T2DM in our present study, 277 genes with known function were submitted to GO analysis and 115 were clustered into different categories. The rest of the 507 genes were either unknown expressed sequence tags or unrecognized by the GO analysis database (Table 4). The 115 analyzed genes were classified into five main categories such as (1) biological regulation, (2) metabolic process, (3) immune system process, (4) biological adhesion, and (5) rhythmic process (Table 4).

\section{Protein-protein interaction analysis}

To better understand the relationships between the functionally related gene groups analyzed by GO, we examined protein-protein interactions between protein products of all 507 genes showing significant difference in gene expression (Fig. 4). Here, Stat3 seems to have a major networking group affecting multiple top GO 
Table 1 Up-regulated genes (>3.0-fold up-regulation)

\begin{tabular}{|c|c|c|c|c|c|c|c|}
\hline Gene function & Description (gene symbol) & Acc. no. & AVE log2 & SD (LOG) & $P$ value (Corr) & Fold change & SD \\
\hline \multirow[t]{7}{*}{ Metabolism } & $\begin{array}{l}\text { Abhydrolase domain containing } \\
\text { 17C (Abhd17c) }\end{array}$ & NM_001100736 & 2.79 & 0.39 & 0.00 & 6.96 & 1.72 \\
\hline & $\begin{array}{l}\text { Alcohol dehydrogenase } 1 \text { (class } \\
\text { I) (Adh1) }\end{array}$ & NM_019286 & 2.43 & 0.99 & 0.00 & 5.38 & 2.78 \\
\hline & $\begin{array}{l}\text { Retinol saturase (all trans retinol } \\
13,14 \text { reductase) (Retsat) }\end{array}$ & NM_145084 & 2.17 & 1.14 & 0.01 & 4.50 & 3.61 \\
\hline & Diacylglycerol kinase, beta (Dgkb) & NM_019304 & 2.07 & 0.34 & 0.00 & 4.21 & 0.82 \\
\hline & $\begin{array}{l}\text { Kallikrein 1-related peptidase C3 } \\
\text { (KIk1c3) }\end{array}$ & NM_001271315 & 1.92 & 0.45 & 0.00 & 3.79 & 1.07 \\
\hline & $\begin{array}{l}\text { Aldo-keto reductase family } 1, \\
\text { member B10 (aldose reductase) } \\
\text { (Akr1b10) }\end{array}$ & NM_001013084 & 1.91 & 0.44 & 0.00 & 3.76 & 1.05 \\
\hline & $\begin{array}{l}\text { Adenosine monophosphate } \\
\text { deaminase } 1 \text { (Ampd1) }\end{array}$ & NM_138876 & 1.61 & 0.71 & 0.00 & 3.06 & 1.56 \\
\hline \multirow[t]{7}{*}{$\begin{array}{l}\text { Signal transduction, regulation of } \\
\text { transcription }\end{array}$} & $\begin{array}{l}\text { Phospholipase A2, group VII } \\
\text { (platelet-activating factor acetyl- } \\
\text { hydrolase, plasma) (Pla2g7) }\end{array}$ & NM_001009353 & 2.23 & 0.29 & 0.00 & 4.68 & 0.88 \\
\hline & $\begin{array}{l}\text { Protein tyrosine phosphatase, } \\
\text { non-receptor type } 13 \text { (Ptpn13) }\end{array}$ & NM_001100789 & 2.13 & 1.06 & 0.00 & 4.38 & 2.18 \\
\hline & Ephrin A2 (Efna2) & NM_001168670 & 1.77 & 0.31 & 0.00 & 3.41 & 0.60 \\
\hline & Crystallin, mu (Crym) & NM_053955 & 1.76 & 0.39 & 0.00 & 3.38 & 0.78 \\
\hline & Cd47 molecule (Cd47) & NM_019195 & 1.74 & 0.26 & 0.00 & 3.34 & 0.51 \\
\hline & Calsyntenin 2 (Clstn2) & NM_134377 & 1.63 & 0.65 & 0.00 & 3.09 & 1.41 \\
\hline & Ring finger protein 187 (Rnf187) & NM_001164264 & 1.61 & 0.34 & 0.00 & 3.06 & 0.63 \\
\hline \multirow[t]{4}{*}{ Receptors, ion channels } & $\begin{array}{l}\text { Potassium voltage-gated channel, } \\
\text { Isk-related family, member } 1 \\
\text { (Kcne1) }\end{array}$ & NM_012973 & 2.72 & 0.82 & 0.00 & 6.57 & 4.07 \\
\hline & $\begin{array}{l}\text { ATPase, } \mathrm{H}+\text { transporting, lysoso- } \\
\text { mal V1 subunit G2 (Atp6v1g2) }\end{array}$ & NM_212490 & 2.53 & 0.60 & 0.00 & 5.77 & 2.02 \\
\hline & $\begin{array}{l}\text { Cholinergic receptor, nicotinic, } \\
\text { alpha } 7 \text { (neuronal) (Chrna7) }\end{array}$ & S53987 & 1.79 & 0.31 & 0.00 & 3.45 & 0.63 \\
\hline & $\begin{array}{l}\text { ATPase, } \mathrm{Ca}++ \text { transporting, } \\
\text { plasma membrane } 2 \text { (Atp2b2) }\end{array}$ & NM_012508 & 1.71 & 0.50 & 0.00 & 3.27 & 0.91 \\
\hline Membrane proteins & $\begin{array}{l}\text { Peroxisomal membrane protein } 4 \\
\text { (Pxmp4) }\end{array}$ & NM_172223 & 2.52 & 0.21 & 0.00 & 5.73 & 0.74 \\
\hline \multirow[t]{2}{*}{ Cell growth and differentiation } & $\begin{array}{l}\text { Transcription elongation factor A } \\
\text { (SII)-like } 7 \text { (Tceal7) }\end{array}$ & NM_001109401 & 1.86 & 0.84 & 0.00 & 3.63 & 1.88 \\
\hline & Jun D proto-oncogene (Jund) & NM_138875 & 1.71 & 0.29 & 0.00 & 3.28 & 0.60 \\
\hline \multirow[t]{2}{*}{ Immune response } & RT1 class Ib, locus T18 (RT1-T18) & NM_001002821 & 2.31 & 0.77 & 0.00 & 4.95 & 2.21 \\
\hline & $\begin{array}{l}\text { 2'-5' oligoadenylate synthetase 1A } \\
\text { (Oas1a) }\end{array}$ & NM_138913 & 1.98 & 0.86 & 0.00 & 3.94 & 2.50 \\
\hline \multirow[t]{2}{*}{ Transport } & $\begin{array}{l}\text { ATPase, } \text { Ca }++ \text { transporting, } \\
\text { plasma membrane } 2 \text { (Atp2b2) }\end{array}$ & NM_012508 & 1.78 & 0.41 & 0.00 & 3.44 & 0.77 \\
\hline & $\begin{array}{l}\text { Solute carrier family } 16 \text { (monocar- } \\
\text { boxylate transporter), member } \\
7 \text { (Slc16a7) }\end{array}$ & NM_017302 & 1.64 & 0.38 & 0.00 & 3.11 & 0.69 \\
\hline \multirow[t]{5}{*}{ Others } & $\begin{array}{l}\text { Guanylate binding protein 1, } \\
\text { interferon-inducible (gbp1) }\end{array}$ & XM_006224278 & 4.80 & 0.49 & 0.00 & 27.84 & 8.96 \\
\hline & Uncharacterized LOC102549588 & XR_362031 & 4.69 & 0.54 & 0.00 & 25.85 & 8.31 \\
\hline & $\begin{array}{l}\text { Twin-arginine translocation path- } \\
\text { way signal }\end{array}$ & & 4.52 & 0.58 & 0.00 & 23.01 & 9.81 \\
\hline & TL0ADA29YA08 mRNA sequence & FQ222105 & 3.27 & 0.42 & 0.00 & 9.64 & 2.34 \\
\hline & $\begin{array}{l}\text { Similar to ribosomal protein L6 } \\
\text { (LOC366145) }\end{array}$ & XM_345411 & 2.94 & 0.59 & 0.00 & 7.70 & 3.03 \\
\hline
\end{tabular}


Table 1 continued

\begin{tabular}{|c|c|c|c|c|c|c|c|}
\hline Gene function & Description (gene symbol) & Acc. no. & AVE log2 & SD (LOG) & $\mathrm{P}$ value (Corr) & Fold change & SD \\
\hline & $\begin{array}{l}\text { Mitochondrial ribosomal protein } \\
\text { S10 (Mrps10) }\end{array}$ & NM_001008859 & 2.86 & 1.24 & 0.00 & 7.28 & 4.07 \\
\hline & $\begin{array}{l}\text { Cd300 molecule-like family mem- } \\
\text { ber G (Cd300lg) }\end{array}$ & XM_003750936 & 2.61 & 0.68 & 0.00 & 6.10 & 2.99 \\
\hline & MRNA decapping enzyme & & 2.32 & 0.35 & 0.00 & 4.99 & 1.11 \\
\hline & $\begin{array}{l}\text { Transmembrane emp24 domain- } \\
\text { containing protein } 5 \text { precursor }\end{array}$ & & 2.14 & 0.28 & 0.00 & 4.41 & 0.72 \\
\hline & $\begin{array}{l}\text { Macrophage activation } 2 \text { like } \\
\text { (Mpa2 I) }\end{array}$ & XM_006221662 & 2.10 & 1.05 & 0.00 & 4.30 & 3.00 \\
\hline & $\begin{array}{l}\text { Similar to interferon-inducible } \\
\text { GTPase (RGD1309362) }\end{array}$ & NM_001024884 & 2.02 & 0.84 & 0.00 & 4.06 & 2.65 \\
\hline & $\begin{array}{l}\text { Myc-like oncogene, s-myc protein } \\
\text { (Mycs) }\end{array}$ & NM_021837 & 2.00 & 0.80 & 0.00 & 4.00 & 1.64 \\
\hline & Uncharacterized LOC102556738 & XR_340771 & 1.96 & 0.44 & 0.00 & 3.89 & 1.10 \\
\hline & $\begin{array}{l}\text { Nuclear casein kinase and cyclin- } \\
\text { dependent kinase substrate } 1 \\
\text { (Nucks1) }\end{array}$ & XM_006249797 & 1.96 & 0.34 & 0.00 & 3.89 & 0.74 \\
\hline & $\begin{array}{l}\text { Transducin-like enhancer of split } \\
6 \text { (E(sp1) homolog, Drosophila) } \\
\text { (Tle6) }\end{array}$ & XM_006241027 & 1.95 & 0.43 & 0.00 & 3.87 & 1.10 \\
\hline & $\begin{array}{l}\text { Transmembrane protein } 132 \mathrm{C} \\
\text { (Tmem132C) }\end{array}$ & XM_002724836 & 1.91 & 0.45 & 0.00 & 3.75 & 1.09 \\
\hline & $\begin{array}{l}\text { CWC25 spliceosome-associated } \\
\text { protein homolog (S. cerevisiae) } \\
\text { (CwC25) }\end{array}$ & NM_001108295 & 1.82 & 0.76 & 0.00 & 3.52 & 1.65 \\
\hline & $\begin{array}{l}\text { Contactin associated protein-like } 2 \\
\text { (Cntnap2) }\end{array}$ & XM_006236412 & 1.79 & 0.39 & 0.00 & 3.47 & 0.84 \\
\hline & $\begin{array}{l}\text { Anaphase promoting complex } \\
\text { subunit } 10 \text { (Anapc10) }\end{array}$ & XM_006255406 & 1.77 & 1.29 & 0.03 & 3.41 & 4.41 \\
\hline & $\begin{array}{l}\text { Deoxycytidine triphosphate } \\
\text { deaminase }\end{array}$ & & 1.73 & 0.35 & 0.00 & 3.32 & 0.74 \\
\hline & Hypothetical protein LOC500028 & NM_001047954 & 1.65 & 0.38 & 0.00 & 3.13 & 0.66 \\
\hline & $\begin{array}{l}\text { RNA binding motif protein } 44 \\
\text { (Rbm44) }\end{array}$ & XM_001066845 & 1.64 & 0.46 & 0.00 & 3.12 & 0.87 \\
\hline & $\begin{array}{l}\text { Trichorhinophalangeal syndrome } \\
\text { I (Trps1) }\end{array}$ & XM_006241626 & 1.62 & 0.39 & 0.00 & 3.08 & 0.69 \\
\hline & $\begin{array}{l}\text { Excision repair cross-complement- } \\
\text { ing rodent repair deficiency, } \\
\text { complementation group } 8 \\
\text { (Ercc8) }\end{array}$ & NM_001107650 & 1.60 & 0.27 & 0.00 & 3.03 & 0.49 \\
\hline & Uncharacterized LOC100912569 & XR_348427 & 1.59 & 0.82 & 0.01 & 3.02 & 1.80 \\
\hline
\end{tabular}

pathways in non-obese T2DM. Moreover, there are proteins interconnected with each other in smaller networking groups including networks of (1) Sdc1; (2) Cyp2e1 and (3) Tef proteins (Fig. 4) affecting the top GO pathways as well (Table 4).

\section{Discussion}

In the present study, our aim was to investigate how cardiac gene expression pattern is influenced by non-obese T2DM. Here we show several characteristics of nonobese T2DM in 15 weeks old male GK rats including decreased body weight, fasting hyperglycemia, hypercholesterolemia, insulin resistance, and impaired glucose tolerance. Moreover, we show increased heart weight and heart weight/body weight ratio in GK rats indicating cardiac hypertrophy. We also demonstrate that non-obese T2DM influences cardiac gene expression pattern by altering transcript levels of several genes. We identified 507 genes which were differentially expressed in the myocardium of GK rats compared to Wistar controls.

The spontaneously diabetic GK rat is a well characterized and recognized model of non-obese type 2 diabetes mellitus. The abnormal glucose regulation in the GK rat develops in association both with impaired insulin secretion and with insulin resistance as reviewed by Östenson and Movassat [29, 32]. At the onset of T2DM, there is a 
Table 2 Down-regulated genes (>3.0-fold down-regulation)

\begin{tabular}{|c|c|c|c|c|c|c|c|}
\hline Gene function & Description (gene symbol) & Acc. no. & AVE $\log 2$ & SD (LOG) & $P$ value (Corr) & Fold change & SD \\
\hline \multirow[t]{5}{*}{ Metabolism } & Transglutaminase 1 (Tgm1) & NM_031659 & -1.98 & 0.55 & 0.0002 & -3.93 & 1.87 \\
\hline & CARBONIC anhydrase 6 (Car6) & NM_001134841 & -2.03 & 0.76 & 0.0002 & -4.08 & 2.61 \\
\hline & $\begin{array}{l}\text { Phenazine biosynthesis-like protein domain } \\
\text { containing } 1 \text { (Pbld1) }\end{array}$ & NM_138530 & -2.14 & 0.68 & 0.0001 & -4.41 & 2.60 \\
\hline & Coproporphyrinogen oxidase (Cpox) & NM_001037095 & -2.32 & 0.45 & 0.0001 & -4.98 & 2.06 \\
\hline & $\begin{array}{l}\text { Prolyl 4-hydroxylase, alpha polypeptide III } \\
\text { (P4ha3) }\end{array}$ & XM_006229769 & -2.36 & 0.38 & 0.0001 & -5.13 & 1.68 \\
\hline \multirow{8}{*}{$\begin{array}{l}\text { Signal transduction, } \\
\text { regulation of } \\
\text { transcription }\end{array}$} & $\begin{array}{l}\text { CAMP responsive element binding protein } 5 \\
\text { (Creb5) }\end{array}$ & XM_006236505 & -1.62 & 0.52 & 0.0001 & -3.07 & 1.26 \\
\hline & $\begin{array}{l}\text { Dual-specificity tyrosine-(Y)-phosphorylation } \\
\text { regulated kinase } 3 \text { (Dyrk3) }\end{array}$ & NM_001024767 & -1.74 & 0.65 & 0.0006 & -3.35 & 1.95 \\
\hline & Hypermethylated in cancer 1 (Hic1) & NM_001107021 & -1.83 & 0.70 & 0.0019 & -3.55 & 2.10 \\
\hline & $\begin{array}{l}\text { Rho guanine nucleotide exchange factor } \\
\text { (GEF) } 5 \text { (Arhgef5) }\end{array}$ & XM_006224892 & -1.96 & 0.47 & 0.0001 & -3.89 & 1.45 \\
\hline & Thyroid hormone responsive (Thrsp) & NM_012703 & -2.28 & 0.98 & 0.0020 & -4.86 & 5.18 \\
\hline & $\begin{array}{l}\text { Cellular retinoic acid binding protein } 2 \\
\text { (Crabp2) }\end{array}$ & NM_017244 & -2.32 & 0.50 & 0.0001 & -4.98 & 2.42 \\
\hline & A kinase (PRKA) anchor protein 3 (Akap3) & NM_001005557 & -2.68 & 0.35 & 0.0000 & -6.39 & 1.90 \\
\hline & Uroplakin 1B (Upk1b) & NM_001024253 & -3.69 & 0.69 & 0.0001 & -12.89 & 7.94 \\
\hline \multirow{8}{*}{$\begin{array}{l}\text { Receptors, ion } \\
\text { channels }\end{array}$} & Interleukin 22 receptor, alpha 2 (II22ra2) & NM_001003404 & -1.62 & 0.93 & 0.0064 & -3.07 & 2.78 \\
\hline & $\begin{array}{l}\text { Neurotrophic tyrosine kinase, receptor, type } 3 \\
\text { (Ntrk3), transcript variant } 3\end{array}$ & NM_019248 & -1.64 & 0.45 & 0.0005 & -3.12 & 1.18 \\
\hline & Adrenoceptor alpha 1D (Adra1d) & NM_024483 & -1.69 & 0.37 & 0.0007 & -3.23 & 1.09 \\
\hline & Lysophosphatidic acid receptor 1 (Lpar1) & NM_053936 & -1.83 & 0.51 & 0.0000 & -3.55 & 1.50 \\
\hline & Prostaglandin F receptor (Ptgfr) & NM_013115 & -1.87 & 0.44 & 0.0000 & -3.65 & 1.40 \\
\hline & $\begin{array}{l}\text { Solute carrier family } 4 \text { (anion exchanger), } \\
\text { member } 1 \text { (Slc4a1) }\end{array}$ & NM_012651 & -2.39 & 0.22 & 0.0000 & -5.23 & 0.94 \\
\hline & Sarcolipin (SIn) & NM_001013247 & -3.00 & 1.41 & 0.0028 & -8.03 & 15.41 \\
\hline & $\begin{array}{l}\text { ATPase, } \mathrm{H}+\text { transporting, lysosomal accessory } \\
\text { protein } 1 \text {-like (Atp6ap1 I) }\end{array}$ & NM_001191843 & -3.59 & 0.31 & 0.0000 & -12.06 & 3.25 \\
\hline Membrane proteins & Sarcolipin (SIn) & CK841541 & -2.51 & 1.08 & 0.0019 & -5.68 & 7.12 \\
\hline \multirow{5}{*}{$\begin{array}{l}\text { Structural protein, } \\
\text { cell adhesion }\end{array}$} & Collagen, type V, alpha 3 (Col5a3) & NM_021760 & -1.78 & 0.59 & 0.0001 & -3.43 & 1.46 \\
\hline & Contactin associated protein 1 (Cntnap1) & NM_032061 & -2.03 & 0.34 & 0.0000 & -4.09 & 1.11 \\
\hline & Myosin binding protein $\mathrm{H}$-like (Mybphl) & NM_001014042 & -2.82 & 1.17 & 0.0011 & -7.08 & 8.55 \\
\hline & Myosin, light chain 7, regulatory (Myl7) & NM_001106017 & -3.37 & 1.66 & 0.0030 & -10.34 & 20.29 \\
\hline & Mesothelin (MsIn) & NM_031658 & -4.46 & 1.44 & 0.0010 & -22.03 & 31.18 \\
\hline \multirow{7}{*}{$\begin{array}{l}\text { Cell growth and } \\
\text { differentiation }\end{array}$} & Ret proto-oncogene (Ret), transcript variant 1 & NM_012643 & -1.64 & 0.44 & 0.0000 & -3.11 & 1.15 \\
\hline & Endothelial cell-specific molecule 1 (Esm1) & NM_022604 & -2.28 & 0.39 & 0.0000 & -4.85 & 1.57 \\
\hline & Neuronatin (Nnat), transcript variant 1 & NM_053601 & -2.34 & 1.34 & 0.0119 & -5.06 & 10.47 \\
\hline & Endothelial cell-specific molecule 1 (Esm1) & NM_022604 & -2.36 & 0.40 & 0.0000 & -5.13 & 1.64 \\
\hline & Epiphycan (Epyc) & NM_001108088 & -2.36 & 1.37 & 0.0083 & -5.14 & 7.64 \\
\hline & Cyclin G1 (Ccng1) & NM_012923 & -3.36 & 0.21 & 0.0000 & -10.29 & 1.82 \\
\hline & Tripartite motif-containing 16 (Trim16) & NM_001135033 & -6.33 & 0.41 & 0.0000 & -80.63 & 28.07 \\
\hline \multirow[t]{7}{*}{ Immune response } & Regenerating islet-derived 3 beta (Reg3b) & NM_053289 & -1.81 & 1.34 & 0.0300 & -3.52 & 5.83 \\
\hline & Inducible T-cell co-stimulator ligand (Icoslg) & XM_006223832 & -1.92 & 0.37 & 0.0000 & -3.79 & 1.16 \\
\hline & $\begin{array}{l}\text { Complement component 4A (Rodgers blood } \\
\text { group) (C4a) }\end{array}$ & NM_031504 & -2.25 & 0.75 & 0.0002 & -4.77 & 3.07 \\
\hline & Chemokine (C-X-C motif) ligand 13 (Cxcl13) & NM_001017496 & -2.48 & 0.78 & 0.0003 & -5.57 & 4.38 \\
\hline & $\begin{array}{l}\text { Similar to immunoglobulin superfamily, mem- } \\
\text { ber } 7 \text { (RGD1559482), }\end{array}$ & NM_001168285 & -2.54 & 0.43 & 0.0000 & -5.83 & 2.19 \\
\hline & CD1d1 molecule (Cd1d1) & NM_017079 & -2.64 & 0.53 & 0.0000 & -6.21 & 2.67 \\
\hline & Chymase 1, mast cell (Cma1) & NM_013092 & -3.95 & 0.45 & 0.0000 & -15.40 & 6.26 \\
\hline
\end{tabular}


Table 2 continued

\begin{tabular}{|c|c|c|c|c|c|c|c|}
\hline Gene function & Description (gene symbol) & Acc. no. & AVE $\log 2$ & SD (LOG) & P value (Corr) & Fold change & SD \\
\hline Transport & Retinol binding protein 4, plasma (Rbp4) & NM_013162 & -2.09 & 1.20 & 0.0131 & -4.27 & 7.22 \\
\hline Hormones & Inhibin alpha (Inha) & NM_012590 & -1.79 & 0.56 & 0.0020 & -3.45 & 1.80 \\
\hline \multirow[t]{32}{*}{ Others } & $\begin{array}{l}\text { Protein Arhgef5 (Source:UniProtKB/ } \\
\text { TrEMBL;Acc:E9PT59) }\end{array}$ & XM_006224892 & -1.62 & 0.54 & 0.0002 & -3.07 & 1.33 \\
\hline & $\begin{array}{l}\text { Hypothetical protein LOC100302372 } \\
\text { (LOC100302372) }\end{array}$ & NM_001162897 & -1.63 & 0.57 & 0.0004 & -3.10 & 1.69 \\
\hline & $\begin{array}{l}\text { (F344/Crij)rearranged mRNA for T-cell receptor } \\
\text { gamma chain (1483 bp) }\end{array}$ & Z27087 & -1.65 & 0.71 & 0.0045 & -3.13 & 1.94 \\
\hline & $\begin{array}{l}\text { Similar to RIKEN cDNA } 1700001 \text { E04 } \\
\text { (LOC367428), mRNA (XM_346135) }\end{array}$ & XM_346135 & -1.65 & 0.25 & 0.0000 & -3.14 & 0.68 \\
\hline & BTB (POZ) domain containing 9 (Btbd9) & XM_006256185 & -1.66 & 0.30 & 0.0000 & -3.15 & 0.73 \\
\hline & $\begin{array}{l}\text { Q99NG8_RAT (Q99NG8) T:G mismatch thy- } \\
\text { mine glycosylase }\end{array}$ & & -1.67 & 0.44 & 0.0001 & -3.17 & 1.24 \\
\hline & Hypothetical protein LOC689316 (LOC689316) & XR_086061 & -1.68 & 0.39 & 0.0000 & -3.21 & 1.02 \\
\hline & Uroplakin 3B-like (Upk3bl) & NM_001109020 & -1.69 & 0.37 & 0.0013 & -3.22 & 1.04 \\
\hline & $\begin{array}{l}\text { NEUU_MOUSE (Q9QXK8) Neuromedin U-23 } \\
\text { precursor (NmU-23) }\end{array}$ & & -1.71 & 0.43 & 0.0000 & -3.28 & 1.10 \\
\hline & Ripply transcriptional repressor 2 (Ripply2) & XM_001064780 & -1.73 & 0.44 & 0.0000 & -3.31 & 1.22 \\
\hline & $\begin{array}{l}\text { Uncharacterized LOC100912446 } \\
\text { (LOC100912446) }\end{array}$ & FQ221838 & -1.73 & 0.64 & 0.0005 & -3.33 & 1.76 \\
\hline & $\begin{array}{l}\text { Similar to TP53-regulating kinase (p53-related } \\
\text { protein kinase) (Nori-2) (LOC685619) }\end{array}$ & XM_002729250 & -1.75 & 0.32 & 0.0000 & -3.37 & 0.84 \\
\hline & $\begin{array}{l}\text { Erythrocyte membrane protein band 4.1-like } \\
3 \text { (Epb41/3) }\end{array}$ & NM_053927 & -1.77 & 0.90 & 0.0057 & -3.41 & 2.69 \\
\hline & $\begin{array}{l}\text { Uncharacterized LOC102556259 } \\
\text { (LOC102556259) }\end{array}$ & XR_355327 & -1.77 & 0.38 & 0.0001 & -3.42 & 1.22 \\
\hline & EF-hand domain family, member D1 (Efhd1) & NM_001109310 & -1.81 & 0.46 & 0.0000 & -3.50 & 1.45 \\
\hline & $\begin{array}{l}\text { Zinc finger and BTB domain containing } 20 \\
\text { (Zbtb20) }\end{array}$ & XM_006248302 & -1.87 & 0.48 & 0.0000 & -3.67 & 1.69 \\
\hline & $\begin{array}{l}\text { Suppressor of glucose, autophagy associated } \\
1 \text { (Soga } 1 \text { ) }\end{array}$ & XM_001067659 & -1.89 & 0.66 & 0.0001 & -3.72 & 2.23 \\
\hline & Protein RGD1562667 & XM_221091 & -1.91 & 0.45 & 0.0000 & -3.75 & 1.49 \\
\hline & $\begin{array}{l}\text { Uncharacterized protein (Source:UniProtKB/ } \\
\text { TrEMBL;Acc:F1LSJ2) (ENSRNOT00000035259) }\end{array}$ & XM_001061015 & -1.93 & 0.61 & 0.0001 & -3.80 & 2.07 \\
\hline & $\begin{array}{l}\text { Uncharacterized LOC102546664 } \\
\text { (LOC102546664) }\end{array}$ & XR_342060 & -1.95 & 0.18 & 0.0000 & -3.87 & 0.58 \\
\hline & $\begin{array}{l}\text { Protein Rsf1 (Source:UniProtKB/ } \\
\text { TrEMBL;Acc:D3ZGQ8) }\end{array}$ & XM_218939 & -1.95 & 1.05 & 0.0109 & -3.87 & 2.89 \\
\hline & $\begin{array}{l}\text { Nucleosome assembly protein } 1 \text {-like } 5 \\
\text { (Nap115) }\end{array}$ & NM_001044293 & -1.97 & 1.04 & 0.0039 & -3.92 & 3.86 \\
\hline & Methyltransferase like 2B (Mett|2b) & NM_001108839 & -2.07 & 0.40 & 0.0000 & -4.20 & 1.36 \\
\hline & $\begin{array}{l}\text { Similar to immunoreceptor Ly49si3 } \\
\text { (LOC690097) }\end{array}$ & XM_003753951 & -2.19 & 0.50 & 0.0001 & -4.55 & 2.20 \\
\hline & Neuronal PAS domain protein 2 (Npas2) & NM_001108214 & -2.23 & 0.47 & 0.0000 & -4.69 & 1.73 \\
\hline & $\begin{array}{l}\text { FM089532 etnofat cDNA clone etno- } \\
\text { fatP0014D18 5', mRNA sequence }\end{array}$ & FM089532 & -2.40 & 0.36 & 0.0001 & -5.28 & 1.54 \\
\hline & Chordin-like 1 (Chrdl1) & NM_199502 & -2.46 & 0.27 & 0.0000 & -5.51 & 1.30 \\
\hline & $\begin{array}{l}\text { Uncharacterized LOC102557390 } \\
\text { (LOC102557390) }\end{array}$ & XR_348511 & -2.54 & 0.48 & 0.0000 & -5.82 & 2.30 \\
\hline & Q7TQ12_RAT (Q7TQ12) Aa1 114 & & -2.62 & 0.32 & 0.0000 & -6.14 & 1.69 \\
\hline & TL0ACA45YL24 mRNA sequence & FQ215947 & -2.65 & 0.48 & 0.0000 & -6.27 & 2.81 \\
\hline & $\begin{array}{l}\text { Aryl hydrocarbon receptor nuclear transloca- } \\
\text { tor-like (Arntl) }\end{array}$ & NM_024362 & -2.75 & 0.54 & 0.0000 & -6.75 & 2.85 \\
\hline & $\begin{array}{l}\text { Similar to RIKEN cDNA } 1500015010 \\
\text { (RGD1305645) }\end{array}$ & NM_001271051 & -2.84 & 0.88 & 0.0003 & -7.17 & 7.06 \\
\hline
\end{tabular}


Table 2 continued

\begin{tabular}{|c|c|c|c|c|c|c|c|}
\hline Gene function & Description (gene symbol) & Acc. no. & AVE log2 & SD (LOG) & $\mathrm{P}$ value (Corr) & Fold change & SD \\
\hline & $\begin{array}{l}\text { Uncharacterized LOC100911508 } \\
\text { (LOC100911508) }\end{array}$ & XR_145872 & -2.86 & 0.30 & 0.0000 & -7.25 & 1.86 \\
\hline & TLOACA40YB18 mRNA sequence. & FQ216879 & -2.99 & 1.21 & 0.0012 & -7.94 & 9.21 \\
\hline & $\begin{array}{l}\text { Family with sequence similarity } 216 \text {, member } \\
\text { B (Fam216b) }\end{array}$ & XM_003751515 & -3.04 & 0.89 & 0.0002 & -8.25 & 6.41 \\
\hline & $\begin{array}{l}\text { SARCO_MOUSE (Q9CQD6) Sarcolipin, com- } \\
\text { plete (TC628765) }\end{array}$ & AW918768 & -3.06 & 1.35 & 0.0020 & -8.33 & 14.57 \\
\hline & Endogenous retrovirus mRNA & AY212271 & -3.51 & 1.47 & 0.0015 & -11.38 & 17.10 \\
\hline & $\begin{array}{l}\text { Uncharacterized LOC } 102552170 \\
\text { (LOC102552170) }\end{array}$ & XM_006224493 & -4.01 & 0.40 & 0.0000 & -16.09 & 5.74 \\
\hline & $\begin{array}{l}\text { O89816_9GAMR (O89816) Envelope glyco- } \\
\text { protein }\end{array}$ & & -4.04 & 0.99 & 0.0001 & -16.49 & 15.56 \\
\hline & $\begin{array}{l}\text { Rat PRRHIS8 mRNA for ribosomal protein S8. } \\
\text { (X56846) }\end{array}$ & X56846 & -4.14 & 0.73 & 0.0000 & -17.63 & 12.05 \\
\hline & Elongator protein 3/MiaB/NifB & & -4.21 & 0.37 & 0.0000 & -18.51 & 5.56 \\
\hline & Endogenous retrovirus mRNA & AY212271 & -4.21 & 1.48 & 0.0006 & -18.52 & 28.67 \\
\hline & $\begin{array}{l}\text { Similar to 60S ribosomal protein L19 } \\
\quad(\text { LOC316856) }\end{array}$ & XM_229366 & -4.46 & 0.84 & 0.0000 & -22.05 & 16.63 \\
\hline & $\begin{array}{l}\text { Uncharacterized LOC102554872 } \\
\text { (LOC102554872) }\end{array}$ & XR_348916 & -4.86 & 0.35 & 0.0000 & -29.02 & 8.07 \\
\hline & WDNM1 homolog (LOC360228) & NM_001003706 & -5.14 & 1.80 & 0.0013 & -35.24 & 76.86 \\
\hline
\end{tabular}

compensatory attempt of the beta cells to release more insulin to defeat insulin resistance. Later this mechanism is insufficient to maintain blood glucose level within a physiological range and finally leads to the functional exhaustion of the surviving beta cells. These stages in the GK model could be also observed in our present study. Blood glucose levels were significantly increased in GK rats at weeks 7, 11 and 15 as compared to controls and there was a statistically significant difference in blood glucose levels in GK rats between the different time points. Blood glucose level in GK rats were significantly lower at week 11 as compared to week 7 or week 15 blood glucose values. Moreover, serum insulin level was significantly increased at week 11 in GK rats as compared to week 7 values. The significantly higher serum insulin level at week 11 could explain the lower blood glucose level at week 11 as compared to week 7 blood glucose values. Serum insulin levels and HOMA-IR were significantly increased at week 7 and 11 showing increasing insulin resistance and compensatory hyperinsulinemia. At week 15 , there was no significant difference in serum insulin level between GK and control animals. However, pancreatic insulin content of GK rats was slightly decreased suggesting the functional exhaustion of pancreatic beta cells. Probably this is the reason why HOMA-IR failed to reach the level of statistical significance in GK rats compared to controls at this time point. Nevertheless, this is not a sign of spontaneous improvement of insulin resistance in GK rats in our present study. These results are in accordance with literature data showing that beta cell mass and insulin production continuously decreases from birth to adulthood in GK rats due to chronic islet inflammation, angiopathy, fibrosis and defective beta cell neogenesis [32].

Surprisingly, only a few studies were performed previously using the qPCR technique to investigate the gene expression changes playing a role in the development of left ventricular hypertrophy and structural remodeling $[20,35,44]$, excitation-contraction coupling $[45,46]$, and lipotoxicity [10] in the hearts of GK rats. Thus, our study is the first to describe overall alterations in the cardiac transcriptome in male GK rats. In our present study, the significantly altered genes can be classified into different clusters (e.g. metabolism, stress response, signal transduction, regulation of transcription, receptors, ion channels, membrane and structural proteins, cell growth and differentiation, immune response, transport, hormones, etc.). Moreover, some other genes without any definite function in the myocardium were also changed in response to DM. The majority of these genes have not been related to nonobese T2DM yet, and therefore, characterization of the functional effects of these genes on the heart in non-obese T2DM is suggested in future mechanistic studies.

\section{Genes related to metabolic alterations in T2DM}

In our present study, several genes related to metabolism were found to be affected in the hearts of GK rats as compared to controls. A group of these altered genes 
Table 3 Confirmation by qRT-PCR

\begin{tabular}{|c|c|c|c|c|c|c|c|}
\hline \multirow[t]{2}{*}{ Gene symbol } & \multirow[t]{2}{*}{ Gene name } & \multirow[t]{2}{*}{ Acc. nr. } & \multicolumn{2}{|c|}{ DNA microarray } & \multicolumn{2}{|l|}{ qRT-PCR } & \multirow[t]{2}{*}{ Confirmed } \\
\hline & & & AVE $(\log 2)$ & Fold change & Fold change & SEM & \\
\hline Adipoq & Adiponectin, C1Q and collagen domain containing & Rn00595250_m1 & -4.99 & -31.78 & -23.64 & 0.02 & Yes \\
\hline Retn & Resistin & Rn00595224_m1 & -4.74 & -26.72 & 31.08 & 14.46 & No \\
\hline Atp1b4 & ATPase, $(\mathrm{Na}+) / \mathrm{K}+$ transporting, beta 4 polypeptide & Rn00584523_m1 & -4.21 & -18.51 & -4.74 & 0.05 & Yes \\
\hline Car3 & Carbonic anhydrase 3 & Rn01461970_m1 & -3.73 & -13.27 & -7.88 & 0.03 & Yes \\
\hline Cma1 & Chymase 1 , mast cell & Rn00565319_m1 & -3.11 & -8.63 & -5.12 & 0.02 & Yes \\
\hline Arntl & Aryl hydrocarbon receptor nuclear translocator-like & Rn00577590_m1 & -2.75 & -6.74 & -2.95 & 0.03 & Yes \\
\hline Tgm1 & Transglutaminase 1, K polypeptide & Rn00581408_m1 & -1.97 & -3.92 & -4.88 & 0.03 & Yes \\
\hline Nnat & Neuronatin (Nnat), transcript variant 1 & Rn00440480_m1 & -1.87 & -3.66 & -4.2 & 0.02 & Yes \\
\hline Ddah1 & Dimethylarginine dimethylaminohydrolase 1 & Rn00574200_m1 & -1.69 & -3.23 & -3.36 & 0.02 & Yes \\
\hline Ntrk3 & Neurotrophic tyrosine kinase, receptor, type 3 & Rn00570389_m1 & -1.69 & -3.23 & -2.33 & 0.06 & Yes \\
\hline Stat3 & Signal transducer and activator of transcription 3 & Rn00562562_m1 & -1.49 & -2.81 & 1.36 & 0.08 & No \\
\hline Dpp4 & Dipeptidylpeptidase 4 & Rn00562910_m1 & -1.35 & -2.55 & -2.11 & 0.03 & Yes \\
\hline Ephx2 & Epoxide hydrolase 2, cytoplasmic & Rn00576023_m1 & -1.33 & -2.51 & -4.23 & 0.02 & Yes \\
\hline Gpc3 & Glypican 3 & Rn00516722_m1 & -1.29 & -2.45 & -2.54 & 0.04 & Yes \\
\hline Fgf18 & Fibroblast growth factor 18 & Rn00433286_m1 & -1.17 & -2.25 & -2.36 & 0.03 & Yes \\
\hline Tfpi & $\begin{array}{l}\text { Tissue factor pathway inhibitor (lipoprotein-associ- } \\
\text { ated coagulation inhibitor) }\end{array}$ & Rn00567935_m1 & -1.10 & -2.14 & 1.12 & 0.06 & No \\
\hline Gckr & Glucokinase (hexokinase 4) regulator & Rn00565467_m1 & -0.98 & -1.97 & -2.09 & 0.05 & N/A \\
\hline Cdkn1a & Cyclin-dependent kinase inhibitor $1 \mathrm{~A}$ & Rn00589996_m1 & -0.93 & -1.91 & -1.34 & 0.04 & N/A \\
\hline Bat5 & HLA-B associated transcript 5 & Rn01525709_g1 & 0.96 & 1.95 & -1.3 & 0.06 & N/A \\
\hline Sele & Selectin E & Rn00594072_m1 & 1.02 & 2.03 & 2.35 & 0.14 & Yes \\
\hline Dbp & $\begin{array}{l}\text { D site of albumin promoter (albumin D-box) bind- } \\
\text { ing protein }\end{array}$ & Rn00497539_m1 & 1.06 & 2.08 & 2.39 & 0.17 & Yes \\
\hline Abcg1 & $\begin{array}{l}\text { ATP-binding cassette, subfamily G (WHITE), mem- } \\
\text { ber } 1\end{array}$ & Rn00585262_m1 & 1.08 & 2.11 & 1.99 & 0.14 & No \\
\hline Cyr61 & Cysteine-rich, angiogenic inducer, 61 & Rn00580055_m1 & 1.14 & 2.20 & 1.58 & 0.12 & No \\
\hline Ephx1 & Epoxide hydrolase 1, microsomal & Rn00563349_m1 & 1.21 & 2.31 & 2.24 & 0.18 & Yes \\
\hline Prkce & Protein kinase C, epsilon & Rn01769089_m1 & 1.28 & 2.43 & 1.09 & 0.08 & No \\
\hline Nurp1 & Nuclear protein, transcriptional regulator, 1 & Rn00586046_m1 & 1.34 & 2.53 & 3.29 & 0.28 & Yes \\
\hline Slc16a7 & $\begin{array}{l}\text { Solute carrier family } 16 \text {, member } 7 \text { (monocarbox- } \\
\text { ylic acid transporter 2) }\end{array}$ & Rn00568872_m1 & 1.77 & 3.41 & 3.21 & 0.19 & Yes \\
\hline Atp2b2 & ATPase, $\mathrm{C}++$ transporting, plasma membrane 2 & Rn01425460_m1 & 1.88 & 3.68 & 3.78 & 0.21 & Yes \\
\hline
\end{tabular}

is involved in cellular ketone metabolic process according to GO and STRING protein-protein interaction analyses (e.g. down-regulation of cytochrome $\mathrm{P} 450$ 2E1, (Cyp2e1); cytochrome P450 2J4, (Cyp2j4); and upregulation of aldehyde dehydrogenase 1 family, member A1, (Aldh1a1); alcohol dehydrogenase 1, (Adh1c); aldo-keto reductase family 1 , member $\mathrm{B} 10,(A k r 1 b 10)$; aldo-keto reductase family 1 , member, $C 12$, (Akr1c12); etc.) (Fig. 4; Table 4). It has been shown that 60 day old GK rats developed increased ketone body production [47], however, there is no literature data available about ketone body metabolism in the heart of GK rats. The ketone body acetone can be converted in vivo to glucose via acetol and pyruvate, and the initial conversion to acetol is catalyzed by Cyp2e1 [48]. It has been shown that
Cyp2e1 knockout mice subjected to starvation to induce ketogenesis develop blood acetone levels much higher than those observed in wild-type mice [48]. In our present study, the down-regulation of Cyp2e1 might be a possible cause of increased ketone body level in the myocardium, however, up-regulation of other genes involved in ketone metabolic process including Aldh1a1; Adh1c; $A k r 1 b 10$; and $A k r 1 c 12$ may be an adaptive response in the myocardium to antagonize elevated ketone body levels. Moreover, Akr1b10 has been shown to be inducible by hyperglycemia in peripheral blood mononuclear cells obtained from patients with diabetic nephropathy. It also could have potential downstream effect of reducing cellular retinoic acid level, which is a key molecule during organogenesis as well as the development of diabetic 
Table 4 Gene ontology analysis

\begin{tabular}{ll}
\hline Category & Term \\
\hline GOTERM_BP_1 & GO:0065007 biological regulation
\end{tabular}

Count

GOTERM_BP_1 GO:0065007 biological regulation

GOTERM_BP_2 GO:0006950 response to stress

GOTERM_BP_2 GO:0050789 regulation of biological process

GOTERM_BP_2 GO:0048518 positive regulation of biological process

GOTERM_BP_2 G0:0048646 anatomical structure formation involved in morphogenesis

GOTERM_BP_2 GO:0009653 anatomical structure morphogenesis

GOTERM_BP_1 GO:0008152 metabolic process

GOTERM_BP_2 GO:0044237 cellular metabolic process

$20.87 \quad 0.00$
9

14

48

$41.74 \quad 0.03$
12.170 .03

$41.74 \quad 0.03$

\footnotetext{
GOTERM_BP_3 GO:0034641 cellular nitrogen compound metabolic process
GOTERM_BP_4 GO:0006575 cellular amino acid derivative metabolic process

GOTERM_BP_3 GO:0010033 $\sim$ response to organic substance

GOTERM_BP_4 GO:0014070 response to organic cyclic substance

GOTERM_BP_3 GO:0006629 lipid metabolic process

GOTERM_BP_4 GO:0006720 isoprenoid metabolic process GOTERM_BP_5 GO:0006720 isoprenoid metabolic process
}

\begin{tabular}{|c|c|c|}
\hline 16.52 & 0.09 & $\begin{array}{l}\text { OCLN, LOC501307, ARNTL, LPCAT2, STAT3, RPS7, ERCC8, } \\
\text { ATP2B2, MCM8, TAF13, ZFP90, CPOX, JUND, TEF, PER2, } \\
\text { CHRNA7, DDAH1, PRPS2, BARD1 }\end{array}$ \\
\hline 3.48 & 0.10 & ATP2B2, OCLN, CHRNA7, LPCAT2 \\
\hline 9.57 & 0.09 & $\begin{array}{l}\text { ALDH1A1, CYP2J4, SDC1, JUND, TRIM16, CHRNA7, } \\
\text { GNB3, EIF2AK2, DDAH1, STAT3, CYR61 }\end{array}$ \\
\hline 4.35 & 0.05 & ALDH1A1, CYP2J4, JUND, CHRNA7, STAT3 \\
\hline 7.83 & 0.08 & $\begin{array}{l}\text { ALDH1A1, CYP2J4, NCF1, CRABP2, PRKAB2, PLA2G7, } \\
\text { SGMS1, LPCAT2, OXSM }\end{array}$ \\
\hline 2.61 & 0.06 & ALDH1A1, CYP2J4, CRABP2 \\
\hline 2.61 & 0.05 & ALDH1A1, CYP2J4, CRABP2 \\
\hline
\end{tabular}

FGF18, PDIA2, GPBP1, C3, CRABP2, TRIM16, ZEB2, LPAR1, ESM1, SGMS1, CCNG1, CD1D1, ALDH1A1, ATP2B2, CD47, NPAS2, DGKB, ZFP90, CXCR6, JUND, PER2, TEF, CHRNA7, CNTNAP1, TRAF6, QSOX1,DDAH1, DPP4, DPT, CYR61, RET, NCF1, NUCKS1, ARHGEF5, PRKAB2, LOC501307, ARNTL, PTGFR, PRKCE, TMEM189, STAT3, FMN1, TRPS1, KLRE1, GNB3, EIF2AK2, ICOSLG, BARD1

NCF1, PDIA2, C3, SGMS1, CD1D1, STAT3, ALDH1A1, ERCC8, SDC1, PLOD2, CHRNA7, TRAF6, EIF2AK2, DDAH1, DPP4, BARD1

FGF18, PDIA2, GPBP1, C3, TRIM16, ZEB2, LPAR1, ESM1, SGMS1, CD1D1, ALDH1A1, ATP2B2, CD47, NPAS2, DGKB, ZFP90, CXCR6, JUND, PER2, TEF, CHRNA7, CNTNAP1, TRAF6, QSOX1, DDAH1, DPP4, DPT, CYR61, RET, NCF1, NUCKS1, ARHGEF5, PRKAB2, ARNTL, PTGFR, PRKCE, TMEM189, STAT3, FMN1, TRPS1, KLRE1, GNB3, EIF2AK2, ICOSLG, BARD1

FGF18, C3, GPBP1, ZEB2, TRIM16, ARNTL, LPAR1, CD1D1, STAT3, FMN1, ALDH1A1, ATP2B2, CD47, NPAS2, JUND, KLRE1, TEF, CHRNA7, EIF2AK2, TRAF6, DDAH1, ICOSLG, CYR61, BARD1

ALDH1A1, ATP2B2, FGF18, RET, RIPPLY2, ZEB2, TRAF6, DDAH1, CYR61

FMN1, ALDH1 A1, ATP2B2, FGF18, SDC1, RET, EFNA2, CRABP2, RIPPLY2, ZEB2, TRAF6, DDAH1, STAT3, CYR61

CYP2J4, OCLN, C3, CRABP2, TRIM50, TRIM16, LPAR1, SGMS1, ALDH1A1, ATP2B2, ERCC8, MCM8, ST6GALNAC3, PLOD2, ZFP90, CPOX, P4HA3, JUND, PER2, TEF, CHRNA7, TRAF6, QSOX1, DDAH1, DPP4, RET, NCF1, PRKAB2, LOC501307, ARNTL, CRYZ, TMEM189, LPCAT2, PRKCE, WEE1, STAT3, RPS7, OXSM, FMN1, TAF13, SLC16A7, AKR1B10, PLA2G7, CMA1, EIF2AK2, CAR6, PRPS2, BARD1

CYP2J4, OCLN, CRABP2, TRIM50, TRIM16, LPAR1, SGMS1, ALDH1A1, ATP2B2, ERCC8, MCM8, ST6GALNAC3, ZFP90, CPOX, JUND, PER2, TEF, CHRNA7, TRAF6, QSOX1, DDAH1, RET, NCF1, PRKAB2, LOC501307, ARNTL, TMEM189, PRKCE, LPCAT2, WEE1, STAT3, RPS7, OXSM, TAF13, SLC16A7, EIF2AK2, CAR6, PRPS2, BARD1 
Table 4 continued

\begin{tabular}{|c|c|c|c|c|c|}
\hline Category & Term & Count & $\%$ & $P$ value & Gene symbol \\
\hline GOTERM_BP_5 & GO:0001523 retinoid metabolic process & 3 & 2.61 & 0.02 & ALDH1A1, CYP2J4, CRABP2 \\
\hline GOTERM_BP_4 & GO:0042573 retinoic acid metabolic process & 2 & 1.74 & 0.10 & ALDH1A1, CRABP2 \\
\hline GOTERM_BP_3 & GO:0044255 cellular lipid metabolic process & 8 & 6.96 & 0.04 & $\begin{array}{l}\text { ALDH1A1, CYP2J4, NCF1, CRABP2, PRKAB2, SGMS1, } \\
\text { LPCAT2, OXSM }\end{array}$ \\
\hline GOTERM_BP_4 & GO:0044255 cellular lipid metabolic process & 8 & 6.96 & 0.04 & $\begin{array}{l}\text { ALDH1A1, CYP2J4, NCF1, CRABP2, PRKAB2, SGMS1, } \\
\text { LPCAT2, OXSM }\end{array}$ \\
\hline GOTERM_BP_3 & GO:0006082 organic acid metabolic process & 8 & 6.96 & 0.06 & $\begin{array}{l}\text { ALDH1A1, CYP2J4, SLC16A7, NCF1, CRABP2, PRKAB2, } \\
\text { DDAH1, OXSM }\end{array}$ \\
\hline GOTERM_BP_4 & GO:0043436 oxoacid metabolic process & 8 & 6.96 & 0.06 & $\begin{array}{l}\text { ALDH1A1, CYP2J4, SLC16A7, NCF1, CRABP2, PRKAB2 } \\
\text { DDAH1, OXSM }\end{array}$ \\
\hline GOTERM_BP_5 & GO:0019752 carboxylic acid metabolic process & 8 & 6.96 & 0.05 & $\begin{array}{l}\text { ALDH1A1, CYP2J4, SLC16A7, NCF1, CRABP2, PRKAB2 } \\
\text { DDAH1, OXSM }\end{array}$ \\
\hline GOTERM_BP_3 & GO:0042180 cellular ketone metabolic process & 8 & 6.96 & 0.07 & $\begin{array}{l}\text { ALDH1A1, CYP2J4, SLC16A7, NCF1, CRABP2, PRKAB2, } \\
\text { DDAH1, OXSM }\end{array}$ \\
\hline GOTERM_BP_3 & GO:0006721 terpenoid metabolic process & 3 & 2.61 & 0.02 & ALDH1A1, CYP2J4, CRABP2 \\
\hline GOTERM_BP_4 & GO:0016101 diterpenoid metabolic process & 3 & 2.61 & 0.02 & ALDH1A1, CYP2J4, CRABP2 \\
\hline GOTERM_BP_5 & GO:0006721 terpenoid metabolic process & 3 & 2.61 & 0.02 & ALDH1A1, CYP2J4, CRABP2 \\
\hline GOTERM_BP_1 & GO:0002376 immune system process & 10 & 8.70 & 0.05 & $\begin{array}{l}\text { CD47, NCF1, C3, RT1-T18, KLRE1, CHRNA7, } \\
\text { TRAF6, CD1D1, DDAH1, DPP4 }\end{array}$ \\
\hline GOTERM_BP_2 & GO:0045321 leukocyte activation & 5 & 4.35 & 0.06 & KLRE1, CHRNA7, TRAF6, CD1D1, DPP4 \\
\hline GOTERM_BP_3 & GO:0045321 leukocyte activation & 5 & 4.35 & 0.05 & KLRE1, CHRNA7, TRAF6, CD1D1, DPP4 \\
\hline GOTERM_BP_4 & GO:0046649 lymphocyte activation & 4 & 3.48 & 0.10 & KLRE1, CHRNA7, CD1D1, DPP4 \\
\hline GOTERM_BP_2 & GO:0006955 immune response & 7 & 6.09 & 0.06 & $\begin{array}{l}\text { CD47, NCF1, C3, RT1-T18, TRAF6, CD1D1, } \\
\text { DDAH1 }\end{array}$ \\
\hline GOTERM_BP_2 & $\begin{array}{l}\text { GO:0002682 regulation of immune system } \\
\text { process }\end{array}$ & 7 & 6.09 & 0.04 & CD47, C3, KLRE1, TRAF6, CD1D1, DDAH1, DPP4 \\
\hline GOTERM_BP_3 & GO:0050776 regulation of immune response & 6 & 5.22 & 0.02 & C3, KLRE1, TRAF6, CD1D1, DDAH1, DPP4 \\
\hline GOTERM_BP_4 & GO:0050776 regulation of immune response & 6 & 5.22 & 0.01 & C3, KLRE1, TRAF6, CD1D1, DDAH1, DPP4 \\
\hline GOTERM_BP_5 & GO:0002253 activation of immune response & 4 & 3.48 & 0.02 & C3, KLRE1, TRAF6, DDAH1 \\
\hline GOTERM_BP_4 & $\begin{array}{l}\text { GO:0002697 regulation of immune effector } \\
\text { process }\end{array}$ & 5 & 4.35 & 0.01 & C3, KLRE1, TRAF6, CD1D1, DPP4 \\
\hline GOTERM_BP_5 & $\begin{array}{l}\text { GO:0002697 regulation of immune effector } \\
\text { process }\end{array}$ & 5 & 4.35 & 0.00 & C3, KLRE1, TRAF6, CD1D1, DPP4 \\
\hline GOTERM_BP_5 & $\begin{array}{l}\text { GO:0002706 regulation of lymphocyte mediated } \\
\text { immunity }\end{array}$ & 5 & 4.35 & 0.00 & C3, KLRE1, TRAF6, CD1D1, DPP4 \\
\hline GOTERM_BP_5 & $\begin{array}{l}\text { GO:0002703 regulation of leukocyte mediated } \\
\text { immunity }\end{array}$ & 5 & 4.35 & 0.00 & C3, KLRE1, TRAF6, CD1D1, DPP4 \\
\hline GOTERM_BP_4 & $\begin{array}{l}\text { GO:0002819 regulation of adaptive immune } \\
\text { response }\end{array}$ & 4 & 3.48 & 0.01 & C3, TRAF6, CD1D1, DPP4 \\
\hline GOTERM_BP_3 & GO:0002682 regulation of immune system process & 7 & 6.09 & 0.04 & CD47, C3, KLRE1, TRAF6, CD1D1, DDAH1, DPP4 \\
\hline GOTERM_BP_4 & $\begin{array}{l}\text { GO:0002684 positive regulation of immune } \\
\text { system process }\end{array}$ & 6 & 5.22 & 0.02 & CD47, C3, KLRE1, TRAF6, CD1D1, DDAH1 \\
\hline GOTERM_BP_2 & GO:0002252 immune effector process & 4 & 3.48 & 0.05 & CD47, NCF1, C3, DDAH1 \\
\hline GOTERM_BP_3 & GO:0002252 immune effector process & 4 & 3.48 & 0.05 & CD47, NCF1, C3, DDAH1 \\
\hline GOTERM_BP_4 & GO:0006968 cellular defense response & 2 & 1.74 & 0.05 & NCF1, DDAH1 \\
\hline GOTERM_BP_1 & GO:0022610 biological adhesion & 7 & 6.09 & 0.09 & $\begin{array}{l}\text { CD47, SDC1, RET, CNTNAP1, COL5A3, BTBD9, } \\
\text { CYR61 }\end{array}$ \\
\hline GOTERM_BP_2 & GO:0007155 cell adhesion & 7 & 6.09 & 0.09 & $\begin{array}{l}\text { CD47, SDC1, RET, CNTNAP1, COL5A3, BTBD9, } \\
\text { CYR61 }\end{array}$ \\
\hline GOTERM_BP_1 & GO:0048511 rhythmic process & 7 & 6.09 & 0.00 & $\begin{array}{l}\text { ALDH1A1, NPAS2, JUND, PER2, TEF, CHRNA7, } \\
\text { ARNTL }\end{array}$ \\
\hline GOTERM_BP_2 & GO:0007623 circadian rhythm & 4 & 3.48 & 0.01 & NPAS2, JUND, PER2, ARNTL \\
\hline
\end{tabular}




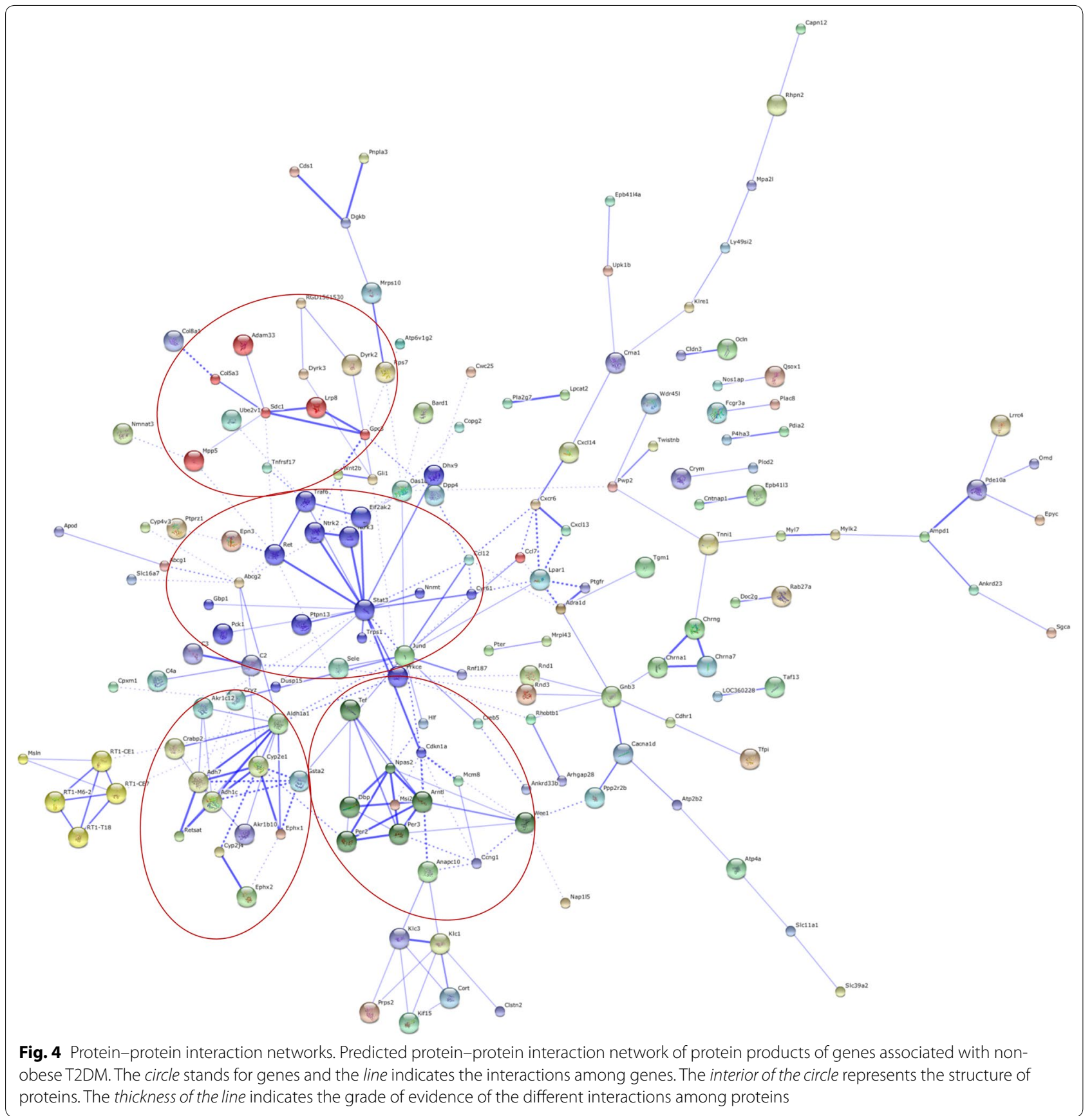

nephropathy [49]. In our present study, non-obese T2DM also influenced expression of genes related to epoxide metabolism (down-regulation of Epoxide hydrolase 2, cytoplasmic, (Ephx2); glutathione S-transferase alpha 2, (Gsta2) and up-regulation of Epoxide hydrolase 1, microsomal, (xenobiotic) (Ephx1) (Fig. 3). Epoxides are possible products of Cyp 450 catalyzed oxidation of aromatic compounds which can lead to toxic, mutagenic or carcinogenic effects [50]. One possibility for their inactivation is the metabolism by epoxide hydrolases. In addition, glutathione-S-transferase catalyzed nucleophilic attack by glutathione may also lead to the inactivation of epoxides [50]. In our present study, Cyp2e1, Cyp2j4, Ephx2 and Gsta2 were down-regulated, showing decreased activity of epoxide metabolism. Moreover, glutathione S-transferase is a well-known enzyme catalyzing the conjugation of reduced glutathione on a wide variety of substrates including reactive oxygen and nitrogen species 
$[51,52]$. Our results suggest that down-regulation of the anti-oxidative gene Gsta2 may contribute to elevated myocardial oxidative/nitrative stress, a phenomenon that has been demonstrated in T2DM by several studies $[53,54]$. Interestingly, we have found overexpression of glutathione S-transferase in the heart in streptozotocininduced DM in neonatal rats [22], metabolic syndrome [21] and cholesterol diet-induced hyperlipidaemia [55] in our previous studies. Moreover, polymorphism of Ephx2 has been shown to be a possible risk factor for developing insulin resistance and T2DM [56]. In addition, polymorphisms of another gene, the cellular retinoic acid binding protein 2 (Crapb2, down-regulated in our present study) has been reported to be a genetic marker of metabolic syndrome [57] and hypercholesterolemia [58].

\section{Genes related to diabetic cardiomyopathy}

One of the major cardiovascular complications of DM is diabetic cardiomyopathy [59,60], which is defined as left ventricular dysfunction with hypertrophy and fibrosis in the absence of hypertension, coronary artery disease and valvular or congenital heart disease [61]. The complex underlying molecular mechanisms of the above-mentioned functional and morphologic changes are not yet clear despite intensive investigations [59-61].

\section{Structure elements}

In our present study, we have shown altered expression of several genes playing a role in myocardial structure formation and potentially related to diabetic cardiomyopathy based on GO and STRING protein-protein interaction analyses. These altered genes include e.g. down-regulation of ADAM metallopeptidase domain 33 (Adam33); collagen, type V, alpha 3, (Col5a3); syndecan 1, (Sdc1); glypican 3 (Gpc3); troponin I type 1 (skeletal, slow) (Tnni1); myosin, light chain 7, regulatory (Myl7); myosin light chain kinase 2 (Mylk2) and upregulation of collagen, type VIII, alpha 1, (Colsa1); etc. (Fig. 4; Table 4). Adam33 is a member of the ADAM protein family encoding a disintegrin and metalloprotease (ADAM) domain 33. It plays a role in cell-cell and cellmatrix interactions, including muscle development and neurogenesis and its polymorphism is associated with the development of T1DM [62]. Moreover, elevated type VIII collagen deposition in human diabetic nephropathy was demonstrated leading to the accumulation of extracellular matrix and periglomerular and interstitial fibrosis. Another ECM component, collagen V, is expressed as $\alpha 1(\mathrm{~V}) 2 \alpha 2(\mathrm{~V})$ heterotrimers, which regulate collagen fibril geometry and strength in several tissues including the pancreas and skeletal muscle. Interestingly, skeletal muscle of Col5 $\mathrm{a}^{-1-}$ mice was defective in glucose uptake and mobilization of intracellular GLUT4 glucose transporter to the plasma membrane in response to insulin thereby leading to a glucose intolerant, insulinresistant, and hyperglycemic phenotype [63]. Membrane proteoglycans Gpc3 and Sdc1 have not yet been demonstrated to play a role in the development of diabetic cardiomyopathy, however, increased expression of the heparan sulfate proteoglycans Gpc1 and Sdc4 has been shown to lead to diastolic dysfunction in streptozotocininduced diabetic rats [64]. In addition, decreased expression of the genes playing a role in contractility including troponin I [65, 66], myosin light chain 7 [67] and myosin light chain kinase 2 [67] could lead to sarcomeric dysfunction and diabetic cardiomyopathy.

\section{Receptors and ion channels}

In our present study, several genes with receptor and/or ion channel function were found to be affected by nonobese T2DM and these genes might play a role in the development of diabetic cardiomyopathy. These genes include e.g. down-regulation of adrenoceptor alpha $1 \mathrm{~d}$ (Adra1d); cholinergic receptor, nicotinic, gamma (muscle) (Chrng); cholinergic receptor, nicotinic, alpha 1 (muscle) (Chrna1); sarcolipin (Sln) and up-regulation of cholinergic receptor, nicotinic, alpha 7 (neuronal) (Chrna7); etc. Down-regulation of Adrald receptor subtype has been previously shown in cardiac hypertrophy [68] and in STZ-induced DM by our research group [22]. Autonomic dysfunction is a serious complication of diabetes and can lead to cardiovascular abnormalities. It could be triggered by advanced glycation end products and reactive oxygen species mediated inactivation of neuronal nicotinic acetylcholine receptors, impairing synaptic transmission in sympathetic ganglia and resulting in autonomic failure [69]. Myocardial down-regulation of Chrng and Chrnal demonstrated in our present study might be another factor of cardiac autonomic dysfunction in diabetes. Moreover, it has been demonstrated that nicotinic cholinergic receptor alpha 7 (Chrna7) null mice showed decreased baroreflex-mediated tachycardia [70]. Sarcolipin $(S \ln )$ is a key regulator of sarcoplasmic reticulum $\mathrm{Ca}^{2+}$-ATPase (SERCA) and mediator of $\beta$-adrenergic responses [71]. It has been shown that $\operatorname{Sln}^{-1-}$ mice are susceptible to develop atrial arrhythmias and interstitial fibrosis due to altered expression of genes encoding collagen [71]. Ablation or mutation of $\operatorname{Sln}$ results in increased SERCA activity and $\mathrm{Ca}^{2+}$ load, causing abnormal intracellular $\mathrm{Ca}^{2+}$ handling and atrial remodeling with dysfunction [71, 72].

\section{Signal transduction, regulation of transcription and biological processes}

A major cluster of significantly altered cardiac genes in response to non-obese T2DM was associated with signal 
transduction, regulation of transcription and biological processes based on GO and STRING protein-protein interaction analyses (e.g. down-regulation of dipeptidylpeptidase 4 (Dpp4); signal transducer and activator of transcription 3 (acute-phase response factor) (Stat3); ret proto-oncogene transcript variant 1 (Ret); neurotrophic tyrosine kinase, receptor, type 2 (Ntrk2); neurotrophic tyrosine kinase, receptor, type 3 (Ntrk3) and up-regulation of Jun D proto-oncogene (Jund); etc.) (Fig. 4; Table 4). Dipeptidyl peptidase-4 is an integral membrane glycoprotein which cleaves $\mathrm{N}$-terminal dipeptides from peptide molecules. The cleaved dipeptides are bioactive molecules regulating the cardiovascular system as well. Dpp4 inhibitors have been reported to be cardioprotective in most of the preclinical and clinical studies in T2DM [73]. In contrast, some cardiovascular outcome studies revealed increased hospitalization rates for heart failure among a subset of DPP4 inhibitor-treated diabetic subjects [74]. Recently a preclinical study has reported that diabetic mice treated with Dpp4 inhibitor exhibited modest cardiac hypertrophy, impairment of cardiac function, and dysregulated expression of genes and proteins controlling inflammation and cardiac fibrosis [75]. In our present study, Dpp4 was down-regulated; therefore it does not seem to be a major and/or necessary regulator in the development of diabetic cardiomyopathy in nonobese T2DM. The transcription factor Stat 3 participates in a wide variety of physiological processes including proliferation, apoptosis, and cardiac survival especially during myocardial ischemia/reperfusion injury, however, its role is contradictory in these aforementioned processes [76]. Several studies have reported that cardiac Stat3 and phospho-Stat 3 expression were reduced in diabetes, which can lead to cardiac dysfunction [76-78]. However, other studies reported that cardiac Stat3 and phospho-Stat3 expression were increased in diabetes leading to hypertrophy $[79,80]$. Furthermore, it has been also reported that Stat3 deficient mice developed dilated cardiomyopathy [76] and patients with dilated cardiomyopathy had severely decreased myocardial Stat 3 expression [81]. In the present study, Stat3 was down-regulated as assessed by microarray, however, qRT-PCR did not confirm these results in our hands. Expression of Stat3 might depend on the duration of DM and the stage of diabetic cardiomyopathy or heart failure. Moreover, there is no literature data available about Stat3 expression in hearts of GK rats; therefore we could not compare our results to others. Surprisingly, down-regulation of Tef and Ret as well as up-regulation of Jund has not been shown previously to play a role in the development of diabetic cardiomyopathy. It has been reported that Ret-deficient mice exhibited a reduced volume of cardiac ganglia and cholinergic innervation of the ventricular conduction system [82]. JunD regulates genes involved in antioxidant defense and hydrogen peroxide $\left(\mathrm{H}_{2} \mathrm{O}_{2}\right)$ production, as well as angiogenesis by controlling VEGF transcription [83]. Furthermore, an important function for JunD is to modulate insulin/insulin-like-growth factor 1 signaling and longevity [83]. Moreover, down-regulation of Ntrk2 and Ntrk3 genes might also play a role in the development of diabetic cardiomyopathy. Interestingly, it has been reported that mice with disrupted Ntrk2 gene lacked a significant proportion of their intramyocardial blood vessels indicating that activation of the Ntrk2 gene was crucial for normal vascularization of the developing heart [84]. In addition, mutations of Ntrk3 gene have been shown in the development of human congenital heart diseases [85].

\section{Genes related to immune and antimicrobial response}

A major cluster of significantly altered cardiac genes in response to non-obese T2DM in GK rats was associated with immune and antimicrobial response based on GO and STRING protein-protein interaction analyses (e.g. complement component 3 (C3); complement component $4 a$ (C4a); chemokine ( $\mathrm{C}-\mathrm{C}$ motif) ligand 12 (Ccl12); chemokine (C-X-C motif) ligand 13 (Cxcl13); chemokine (C-X-C motif) ligand 14 (Cxcl14); chymase 1 , mast cell (Cma1) and up-regulation of chemochine ( $C-X-C$ motif) receptor 6 (Cxcr6); killer cell lectin-like receptor, family E, member 1 (Klre1); etc.) which is in line with the wellknown increased susceptibility to infections in DM [86, 87].

\section{Novel genes previously not related to diabetic alterations in the heart}

Many of the genes showing altered expression in diabetic hearts in the present study have not yet been related to any diabetic alterations in the heart (e.g. down-regulation of low density lipoprotein receptor-related protein 8, apolipoprotein E receptor (Lrp8) and mesothelin $(M \sin )$ and up-regulation of kallikrein 1-related peptidase C3 (Klk1c3) and Epsin 3 (Epn3); etc.) (Table 4). Some other altered genes were not classified into specific functional clusters or indicated as yet uncharacterized, predicted genes and fragments (e.g. up-regulation of hydroxyacyl glutathione hydrolase-like and Similar to hepatic leukemia factor (LOC690286) or down-regulation of uncharacterized LOC102546816 and similar to protein C17orf72; etc.) (Table 4), the relevance of which should not be ignored.

\section{Limitations}

Our study is not without limitations. Insulin resistance was estimated in our study by determining HOMAIR rather than the gold standard hyperinsulinemic 
euglycemic clamp technique. Nevertheless, the presence of insulin resistance in GK rats has been confirmed in several studies [88-91]. Although detailed morphological or histological analysis of GK hearts is lacking, our data including increased heart weight, heart weight to body weight ratio and coronary flow together with literature data suggest the development of LV hypertrophy in our model. Although our study does not specify which cell type (i.e. cardiomyocyte, fibroblast, smooth muscle cell, etc.) may be responsible for the observed alterations of cardiac gene expression due to DM, the contribution of cardiomyocytes is likely the most significant [92, 93]. In addition, it is unclear whether significantly altered gene expression changes at the mRNA level are further translated to changes in protein levels and if gene expression changes are causes or consequences of the development of diabetic cardiomyopathy, therefore, additional indepth mechanistic studies should be carried out.

\section{Conclusions}

In summary, we have found that 15 week old male GK rats develop non-obese T2DM and we have demonstrated for the first time that non-obese T2DM is associated with a profound modification of the cardiac transcriptome. Some of the genes showing altered expression in the hearts of GK rats have been implicated in non-obese T2DM previously by other techniques. Some of the genes showing altered expression in our present study in non-obese T2DM have been reported to be associated with cardiac alterations in obese T2DM or T1DM models. Many of the genes showing significant expressional alterations in GK rat hearts in the present study have not been associated with non-obese T2DM previously. We conclude that non-obese T2DM alters the gene expression pattern of the myocardium. These altered genes may be involved in the development of cardiac pathologies in the state of non-obese type 2 diabetes mellitus. Based on our exploratory results, future studies should be carried out to investigate the precise role of specific genes in the development of cardiac consequences of non-obese T2DM to obtain deeper mechanistic insight.

\section{Additional files}

Additional file 1. Raw data of the DNA microarray.

Additional file 2. Additional Tables. complementary deoxyribonucleic acid; Chrna1: cholinergic receptor, nicotinic, alpha 1 (muscle); Chrna7: cholinergic receptor, nicotinic, alpha 7 (neuronal); Chrng: cholinergic receptor, nicotinic, gamma (muscle); Cma1: chymase 1, mast cell; Col5a3: collagen, type V, alpha 3; Col8a1: collagen, type VIII, alpha 1; Crapb2: cellular retinoic acid binding protein 2; $\mathrm{Cxcl} 13$ : chemokine (C-X-C motif) ligand 13; Cxcr6: chemochine (C-X-C motif) receptor 6; Cyp2e1: cytochrome P450 2E1; Cyp2j4: cytochrome P450 2J4; DAVID: Database for Annotation, Visualization and Integrated Discovery; DCM: diabetic cardiomyopathy; DNA: deoxyribonucleic acid; Dpp4: dipeptidylpeptidase 4; ELISA: enzyme linked immunosorbent assay; Ephx1: epoxide hydrolase 1, microsomal, (xenobiotic); Ephx2: epoxide hydrolase 2, cytoplasmic; Epn3: epsin 3; GAPDH: glyceraldehyde-3-phosphate dehydrogenase; GK rat: Goto-Kakizaki rat; GLUT4: glucose transporter 4; GO: gene ontology; Gpc3: glypican 3; Gsta2: glutathione S-transferase alpha 2; HOMA-IR: homeostasis model assessmentestimated insulin resistance; HPRT: hypoxanthine phosphoribosyl transferase; Jund: Jun D proto-oncogene; KIk1c3: kallikrein 1-related peptidase C3; KIre1: killer cell lectin-like receptor, family E, member 1; Lrp8: low density lipoprotein receptor-related protein 8, apolipoprotein E receptor; LV: left ventricular; mRNA: messenger ribonucleic acid; MsIn: mesothelin; Myl7: myosin, light chain 7, regulatory; Mylk2: myosin light chain kinase 2; Ntrk: neurotrophic tyrosine kinase, receptor; OGTT: oral glucose tolerance test; qRT-PCR: quantitative real-time polymerase chain reaction; Ret: ret proto-oncogene transcript variant 1; RNA: ribonucleic acid; RPS18: ribosomal protein S18; Sdc1: syndecan 1; SEM: standard error of mean; SERCA: sarcoplasmic reticulum $\mathrm{Ca}^{2+}$-ATPase; SIn: sarcolipin; Stat3: signal transducer and activator of transcription 3; STZ: streptozotocin; T1DM: type 1 diabetes mellitus; T2DM: type 2 diabetes mellitus; Tnni1: troponin I type 1 (skeletal, slow); ZDF rat: Zucker Diabetic Fatty rat.

\section{Author contributions and consent for publication}

PF, CC and TC conception and design of research; MS, GS, VF, MP, KE, RG, AS, JP and CC performed experiments; MS, GS, VF, MP, KE, RG, AS, AZ, CC, and TC analysed data; MS, GS, VF, MP, KE, RG, AS, AZ, CC, and TC interpreted results of experiments; MS, SA, and MP prepared figures and tables; MS and TC drafted manuscript; MS, PF, CC, and TC edited and revised manuscript; MS, GS, VF, $M P, K E, R G, A S, J P, A Z, P F, C C$, and TC approved final version of manuscript. All authors read and approved the final manuscript.

\section{Author details}

${ }^{1}$ Department of Biochemistry, Faculty of Medicine, University of Szeged, Dóm tér 9, Szeged 6720, Hungary. ${ }^{2}$ Department of Physiology, Anatomy and Neuroscience, Faculty of Science and Informatics, University of Szeged, Szeged, Hungary. ${ }^{3}$ Department of Genetics, Cell- and Immunobiology, Semmelweis University, Budapest, Hungary. ${ }^{4}$ Pharmahungary Group, Szeged, Hungary. ${ }^{5}$ Department of Pharmacology and Pharmacotherapy, Semmelweis University, Budapest, Hungary.

\section{Acknowledgements}

We acknowledge the excellent technical support of Szilvia Török and Anikó Pósa for blood sampling and insulin assays, of Ágnes Semsei for performing qRT-PCR measurements, Ágnes Zvara for advices in protein-protein interaction analysis and Jeremy Parrott language editor for proofreading the manuscript.

\section{Availability of data and materials}

The conclusions of the manuscript are based on relevant data sets available in the manuscript and in Additional file tables.

\section{Competing interests}

Béres Pharmaceuticals Ltd., Pharmahungary Group and University of Szeged had a consortial grant funded by the National Development Agency (MED_ FOOD TECH_08-A1-2008-0275). P.F. is the founder and CEO and T.C. and C.C. were involved in the management of Pharmahungary Group, a pharmaceuti$\mathrm{cal} /$ biotechnological company partially financing the current study.

\section{Sources of funding}

Ányos Jedlik program (MED_FOOD TECH_08-A1-2008-0275), Gábor Baross program (DA_TECH_07-METABBET), the Hungarian Scientific Research Fund (OTKA K115990), CC holds a "Bolyai Fellowship" from the Hungarian Academy of Sciences. G.S. is financed by the MTA Postdoctoral Fellowship Programme. This article was supported by GINOP-2.3.2-15-2016-00006 financed by the Hungarian Government and co-financed by the European Structural Fund. 
Received: 11 April 2016 Accepted: 14 July 2016

Published online: 05 August 2016

\section{References}

1. Korkmaz-Icöz S, Lehner A, Li S, Vater A, Radovits T, Hegedűs P, et al. Mild Type 2 diabetes mellitus reduces the susceptibility of the heart to ischemia/reperfusion injury: identification of underlying gene expression changes. J Diabetes Res. 2015;2015:396414.

2. Global status report on noncommunicable diseases 2014. Geneva: WHO; 2014. http://www.who.int/global-coordination-mechanism/publications/ global-status-report-ncds-2014-eng.pdf. Accessed 29 Mar 2016.

3. Danaei G, Finucane MM, Lu Y, Singh GM, Cowan MJ, Paciorek CJ, et al. National, regional, and global trends in fasting plasma glucose and diabetes prevalence since 1980: systematic analysis of health examination surveys and epidemiological studies with 370 country-years and 2.7 million participants. Lancet. 2011;378:31-40.

4. Whiting DR, Guariguata L, Weil C, Shaw J. IDF diabetes atlas: global estimates of the prevalence of diabetes for 2011 and 2030. Diabetes Res Clin Pract. 2011;94:311-2.

5. Wild S, Roglic G, Green A, Sicree R, King H. Global prevalence of diabetes: estimates for the year 2000 and projections for 2030. Diabetes Care. 2004:27:1047-53.

6. Zimmet P, Alberti KG, Shaw J. Global and societal implications of the diabetes epidemic. Nature. 2001:414:782-7.

7. Vaag A, Lund SS. Non-obese patients with type 2 diabetes and prediabetic subjects: distinct phenotypes requiring special diabetes treatment and (or) prevention? Appl Physiol Nutr Metab. 2007:32:912-20.

8. Dalton M, Cameron AJ, Zimmet PZ, Shaw JE, Jolley D, Dunstan DW, et al. Waist circumference, waist-hip ratio and body mass index and their correlation with cardiovascular disease risk factors in Australian adults. J Intern Med. 2003;254:555-63.

9. Mohan V, Deepa R. Adipocytokines and the expanding 'Asian Indian Phenotype'. J Assoc Physicians India. 2006:54:685-6.

10. Devanathan S, Nemanich ST, Kovacs A, Fettig N, Gropler RJ, Shoghi KI. Genomic and metabolic disposition of non-obese type 2 diabetic rats to increased myocardial fatty acid metabolism. PLoS ONE. 2013;8:e78477.

11. Manson JE, Colditz GA, Stampfer MJ, Willett WC, Krolewski AS, Rosner $B$, et al. A prospective study of maturity-onset diabetes mellitus and risk of coronary heart disease and stroke in women. Arch Intern Med. 1991:151:1141-7.

12. Wilson PW. Diabetes mellitus and coronary heart disease. Endocrinol Metab Clin North Am. 2001;30:857-81.

13. Willett WC, Dietz WH, Colditz GA. Guidelines for healthy weight. N Engl Med 1999:341:427-34

14. Adlerberth AM, Rosengren A, Wilhelmsen L. Diabetes and long-term risk of mortality from coronary and other causes in middle-aged Swedish men. A general population study. Diabetes Care. 1998;21:539-45.

15. Asrih M, Steffens S. Emerging role of epigenetics and miRNA in diabetic cardiomyopathy. Cardiovasc Pathol. 2013;22(2):117-25.

16. Wang J, Song Y, Wang Q, Kralik PM, Epstein PN. Causes and characteristics of diabetic cardiomyopathy. Rev Diabet Stud. 2006;3:108-17.

17. Rubler S, Dlugash J, Yuceoglu YZ, Kumral T, Branwood AW, Grishman A. New type of cardiomyopathy associated with diabetic glomerulosclerosis. Am J Cardiol. 1972;30:595-602.

18. Voulgari C, Papadogiannis D, Tentolouris N. Diabetic cardiomyopathy: from the pathophysiology of the cardiac myocytes to current diagnosis and management strategies. Vasc Health Risk Manag. 2010;6:883-903.

19. Solomon SD, St John Sutton M, Lamas GA, Plappert T, Rouleau JL, Skali H, et al. Ventricular remodeling does not accompany the development of heart failure in diabetic patients after myocardial infarction. Circulation. 2002;106:1251-5

20. Chandler MP, Morgan EE, McElfresh TA, Kung TA, Rennison JH, Hoit $B D$, et al. Heart failure progression is accelerated following myocardial infarction in type 2 diabetic rats. Am J Physiol Heart Circ Physiol. 2007;293:H1609-16.

21. Sárközy M, Zvara A, Gyémánt N, Fekete V, Kocsis GF, Pipis J, et al. Metabolic syndrome influences cardiac gene expression pattern at the transcript level in male ZDF rats. Cardiovasc Diabetol. 2013:12:16.
22. Sárközy M, Szűcs G, Pipicz M, Zvara Á, Éder K, Fekete V, et al. The effect of a preparation of minerals, vitamins and trace elements on the cardiac gene expression pattern in male diabetic rats. Cardiovasc Diabetol. $2015 ; 14: 85$

23. Ghanaat-Pour H, Huang Z, Lehtihet M, Sjöholm A. Global expression profiling of glucose-regulated genes in pancreatic islets of spontaneously diabetic Goto-Kakizaki rats. J Mol Endocrinol. 2007:39:135-50.

24. Homo-Delarche F, Calderari S, Irminger JC, Gangnerau MN, Coulaud J, Rickenbach K, et al. Islet inflammation and fibrosis in a spontaneous model of type 2 diabetes, the GK rat. Diabetes. 2006;55:1625-33. Erratum in: Diabetes. 2006: 55:2665.

25. Zhou H, Saito S, Piao G, Liu ZP, Wang J, Horimoto K, et al. Network screening of Goto-Kakizaki rat liver microarray data during diabetic progression. BMC Syst Biol. 2011;5(Suppl 1):S16.

26. Nie J, Xue B, Sukumaran S, Jusko WJ, Dubois DC, Almon RR. Differential muscle gene expression as a function of disease progression in GotoKakizaki diabetic rats. Mol Cell Endocrinol. 2011;338:10-7.

27. Herrera BM, Lockstone HE, Taylor JM, Ria M, Barrett A, Collins S, et al. Global microRNA expression profiles in insulin target tissues in a spontaneous rat model of type 2 diabetes. Diabetologia. 2010;53:1099-109.

28. Abdul-Rahman O, Sasvari-Szekely M, Ver A, Rosta K, Szasz BK, Kereszturi E, et al. Altered gene expression profiles in the hippocampus and prefrontal cortex of type 2 diabetic rats. BMC Genom. 2012;13:81.

29. Ostenson CG, Efendic S. Islet gene expression and function in type 2 diabetes; studies in the Goto-Kakizaki rat and humans. Diabetes Obes Metab. 2007;9(Suppl 2):180-6.

30. Goto Y, Kakizaki M, Masaki N. Production of spontaneous diabetic rats by repetition of selective breeding. Tohoku J Exp Med. 1976;119:85-90.

31. Goto Y, Suzuki K, Ono T, Sasaki M, Toyota T. Development of diabetes in the non-obese NIDDM rat (GK rat). Adv Exp Med Biol. 1988;246:29-31.

32. Movassat J, Calderari S, Fernández E, Martín MA, Escrivá F, Plachot C, et al. Type 2 diabetes - a matter of failing beta-cell neogenesis? Clues from the GK rat model. Diabetes Obes Metab. 2007:9(Suppl 2):187-95.

33. Galli J, Li LS, Glaser A, Ostenson CG, Jiao H, Fakhrai-Rad H, et al. Genetic analysis of non-insulin dependent diabetes mellitus in the GK rat. Nat Genet. 1996;12:31-7.

34. Ostenson CG. The pathophysiology of type 2 diabetes mellitus: an overview. Acta Physiol Scand. 2001;171:241-7.

35. D'Souza A, Howarth FC, Yanni J, Dobryznski H, Boyett MR, Adeghate E, Bidasee KR, Singh J. Left ventricle structural remodelling in the prediabetic Goto-Kakizaki rat. Exp Physiol. 2011;96:875-88.

36. Grönholm T, Cheng ZJ, Palojoki E, Eriksson A, Bäcklund T, Vuolteenaho O, Finckenberg P, Laine M, Mervaala E, Tikkanen I. Vasopeptidase inhibition has beneficial cardiac effects in spontaneously diabetic Goto-Kakizaki rats. Eur J Pharmacol. 2005;519:267-76.

37. Kocsis GF, Sárközy M, Bencsik P, Pipicz M, Varga ZV, Pálóczi J, et al. Preconditioning protects the heart in a prolonged uremic condition. Am J Physiol Heart Circ Physiol. 2012;303:H1229-36.

38. Sárközy M, Fekete V, Szűcs G, Török S, Szűcs C, Bárkányi J, et al. Antidiabetic effect of a preparation of vitamins, minerals and trace elements in diabetic rats: a gender difference. BMC Endocr Disord. 2014;14:72.

39. Barr EL, Cameron AJ, Balkau B, Zimmet PZ, Welborn TA, Tonkin AM, et al. HOMA insulin sensitivity index and the risk of all-cause mortality and cardiovascular disease events in the general population: the Australian Diabetes, Obesity and Lifestyle Study (AusDiab) study. Diabetologia. 2010;53:79-88.

40. Csont T, Bereczki E, Bencsik P, Fodor G, Görbe A, Zvara A, et al. Hypercholesterolemia increases myocardial oxidative and nitrosative stress thereby leading to cardiac dysfunction in apoB-100 transgenic mice. Cardiovasc Res. 2007:76:100-9.

41. Csont T, Sárközy M, Szűcs G, Szűcs C, Bárkányi J, Bencsik P, et al. Effect of a multivitamin preparation supplemented with phytosterol on serum lipids and infarct size in rats fed with normal and high cholesterol diet. Lipids Health Dis. 2013:12:138.

42. Skov V, Thomassen M, Riley CH, Jensen MK, Bjerrum OW, Kruse TA, et al. Gene expression profiling with principal component analysis depicts the biological continuum from essential thrombocythemia over polycythemia vera to myelofibrosis. Exp Hematol. 2012;40(771-780):e19.

43. Weirauch MT. Gene coexpression networks for the analysis of DNA microarray data. Applied statistics for network biology: methods in systems biology. 2011;. doi:10.1002/9783527638079.ch11. 
44. D'Souza A, Howarth FC, Yanni J, Dobrzynski H, Boyett MR, Adeghate E, Bidasee KR, Singh J. Chronic effects of mild hyperglycaemia on left ventricle transcriptional profile and structural remodelling in the spontaneously type 2 diabetic Goto-Kakizaki rat. Heart Fail Rev. 2014;19:65-74.

45. Salem KA, Qureshi MA, Sydorenko V, Parekh K, Jayaprakash P, lqbal T, Singh J, Oz M, Adrian TE, Howarth FC. Effects of exercise training on excitation-contraction coupling and related mRNA expression in hearts of Goto-Kakizaki type 2 diabetic rats. Mol Cell Biochem. 2013;380:83-96.

46. Gaber EM, Jayaprakash P, Qureshi MA, Parekh K, Oz M, Adrian TE, Howarth FC. Effects of a sucrose-enriched diet on the pattern of gene expression, contraction and $\mathrm{Ca}(2+)$ transport in Goto-Kakizaki type 2 diabetic rat heart. Exp Physiol. 2014;99:881-93.

47. Zhao LC, Zhang XD, Liao SX, Gao HC, Wang HY, Lin DH. A metabonomic comparison of urinary changes in Zucker and GK rats. J Biomed Biotechnol. 2010;2010:431894.

48. Palmer M. Combination treatment of epilepsy with ketogenic diet and concurrent pharmacological inhibition of cytochrome P450 2E1. Med Hypotheses. 2013;80:481-5.

49. Shaw N, Yang B, Millward A, Demaine A, Hodgkinson A. AKR1B10 is induced by hyperglycaemia and lipopolysaccharide in patients with diabetic nephropathy. Cell Stress Chaperones. 2014;19:281-7.

50. Schladt L, Wörner W, Setiabudi F, Oesch F. Distribution and inducibility of cytosolic epoxide hydrolase in male Sprague-Dawley rats. Biochem Pharmacol. 1986;35:3309-16.

51. Douglas KT. Mechanism of action of glutathione-dependent enzymes. Adv Enzymol Relat Areas Mol Biol. 1987;59:103-67.

52. L'Ecuyer T, Allebban Z, Thomas R, Vander Heide R. Glutathione S-transferase overexpression protects against anthracycline-induced $\mathrm{H} 9 \mathrm{C} 2$ cell death. Am J Physiol Heart Circ Physiol. 2004;286:H2057-64.

53. Bhatt NM, Aon MA, Tocchetti CG, Shen X, Dey S, Ramirez-Correa G, et al. Restoring redox balance enhances contractility in heart trabeculae from type 2 diabetic rats exposed to high glucose. Am J Physiol Heart Circ Physiol. 2015;308:H291-302.

54. Mandavia CH, Aroor AR, Demarco VG, Sowers JR. Molecular and metabolic mechanisms of cardiac dysfunction in diabetes. Life Sci. 2013;92:601-8.

55. Puskas LG, Nagy ZB, Giricz Z, Onody A, Csonka C, Kitajka K, et al. Cholesterol diet-induced hyperlipidemia influences gene expression pattern of rat hearts: a DNA microarray study. FEBS Lett. 2004;562:99-104.

56. Ghattas MH, Amer MA. Possible role of microsomal epoxide hydrolase gene polymorphism as a risk factor for developing insulin resistance and type 2 diabetes mellitus. Endocrine. 2012;42:577-83.

57. Salazar J, Ferré R, Vallvé JC, Pocoví M, Cabezas MC, Masana L, et al. Two novel single nucleotide polymorphisms in the promoter of the cellular retinoic acid binding protein II gene (CRABP-II). Mol Cell Probes. 2003;17:21-3.

58. Salazar J, Guardiola M, Ferré R, Coll B, Alonso-Villaverde C, WinklhoferRoob BM, et al. Association of a polymorphism in the promoter of the cellular retinoic acid-binding protein II gene (CRABP2) with increased circulating low-density lipoprotein cholesterol. Clin Chem Lab Med. 2007:45:615-20.

59. Bugger $\mathrm{H}$, Abel ED. Molecular mechanisms of DCM. Diabetologia. 2014;57:660-71

60. Dhalla NS, Takeda N, Rodriguez-Leyva D, Elimban V. Mechanisms of subcellular remodeling in heart failure due to diabetes. Heart Fail Rev. 2014;19:87-99.

61. Wang J, Song Y, Wang Q, Kralik PM, Epstein PN. Causes and characteristics of DCM. Rev Diabet Stud. 2006;3:108-17.

62. Smyth DJ, Howson JM, Payne F, Maier LM, Bailey R, Holland K, et al. Analysis of polymorphisms in 16 genes in type 1 diabetes that have been associated with other immune-mediated diseases. BMC Med Genet. 2006;7:20.

63. Huang G, Ge G, Wang D, Gopalakrishnan B, Butz DH, Colman RJ, et al. $a 3(V)$ collagen is critical for glucose homeostasis in mice due to effects in pancreatic islets and peripheral tissues. J Clin Invest. 2011;121:769-83.

64. Strunz CM, Matsuda M, Salemi VM, Nogueira A, Mansur AP, Cestari IN, et al. Changes in cardiac heparan sulfate proteoglycan expression and streptozotocin-induced diastolic dysfunction in rats. Cardiovasc Diabetol. 2011;10:35.

65. Aydemir-Koksoy A, Bilginoglu A, Sariahmetoglu M, Schulz R, Turan B. Antioxidant treatment protects diabetic rats from cardiac dysfunction by preserving contractile protein targets of oxidative stress. J Nutr Biochem. 2010;21:827-33.

66. Dhalla N, Takeda N, Rodriguez-Leyva D, Elimban V. Mechanisms of subcellular remodeling in heart failure due to diabetes. Heart Fail Rev. 2014;19:87-99.

67. Liu X, Takeda N, Dhalla NS. Myosin light-chain phosphorylation in diabetic cardiomyopathy in rats. Metabolism. 1997:46:71-5.

68. Rokosh DG, Stewart AF, Chang KC, Bailey BA, Karliner JS, Camacho SA, et al. Alpha1-adrenergic receptor subtype mRNAs are differentially regulated by alpha1-adrenergic and other hypertrophic stimuli in cardiac myocytes in culture and in vivo. Repression of alpha1B and alpha1D but induction of alpha1C. J Biol Chem. 1996;271:5839-43.

69. Chandna AR, Nair M, Chang C, Pennington PR, Yamamoto Y, Mousseau $D D$, et al. RAGE mediates the inactivation of nAChRs in sympathetic neurons under high glucose conditions. Eur J Neurosci. 2015;41:341-51.

70. Franceschini D, Orr-Urtreger A, Yu W, Mackey LY, Bond RA, Armstrong D, et al. Altered baroreflex responses in alpha7 deficient mice. Behav Brain Res. 2000;113:3-10.

71. Xie LH, Shanmugam M, Park JY, Zhao Z, Wen H, Tian B, et al. Ablation of sarcolipin results in atrial remodeling. Am J Physiol Cell Physiol. 2012;302:C1762-71

72. Shanmugam M, Li D, Gao S, Fefelova N, Shah V, Voit A, et al. Cardiac specific expression of threonine 5 to alanine mutant sarcolipin results in structural remodeling and diastolic dysfunction. PLOS ONE. 2015;10:e0115822.

73. Bando YK, Murohara T. Heart Failure as a Comorbidity of Diabetes: role of Dipeptidyl Peptidase 4. J Atheroscler Thromb. 2016;23:147-54.

74. Son JW, Kim S. Dipeptidyl Peptidase 4 Inhibitors and the Risk of Cardiovascular Disease in Patients with Type 2 Diabetes: a Tale of Three Studies. Diabetes Metab J. 2015;39:373-83.

75. Mulvihill EE, Varin EM, Ussher JR, Campbell JE, Bang KW, Abdullah T, et al. Inhibition of Dipeptidyl Peptidase-4 impairs ventricular function and promotes cardiac fibrosis in high fat-fed diabetic mice. Diabetes. 2016;65:742-54.

76. Hilfiker-Kleiner D, Hilfiker A, Fuchs M, Kaminski K, Schaefer A, Schieffer $B$, et al. Signal transducer and activator of transcription 3 is required for myocardial capillary growth, control of interstitial matrix deposition, and heart protection from ischemic injury. Circ Res. 2004;95:187-95.

77. Xu J, Lei S, Liu Y, Gao X, Irwin MG, Xia ZY, et al. Antioxidant N-acetylcysteine attenuates the reduction of Brg1 protein expression in the myocardium of type 1 diabetic rats. J Diabetes Res. 2013;2013:716219.

78. Wang T, Qiao S, Lei S, Liu Y, Ng KF, Xu A, et al. N-acetylcysteine and allopurinol synergistically enhance cardiac adiponectin content and reduce myocardial reperfusion injury in diabetic rats. PLoS ONE. 2011;6:e23967.

79. Sun X, Chen RC, Yang ZH, Sun GB, Wang M, Ma XJ, et al. Taxifolin prevents diabetic cardiomyopathy in vivo and in vitro by inhibition of oxidative stress and cell apoptosis. Food Chem Toxicol. 2014;63:221-32.

80. Wang L, Li J, Li D. Losartan reduces myocardial interstitial fibrosis in diabetic cardiomyopathy rats by inhibiting JAK/STAT signaling pathway. Int J Clin Exp Pathol. 2015;8:466-73.

81. Podewski EK, Hilfiker-Kleiner D, Hilfiker A, Morawietz H, Lichtenberg A, Wollert KC, et al. Alterations in Janus kinase (JAK)-signal transducers and activators of transcription (STAT) signaling in patients with end-stage dilated cardiomyopathy. Circulation. 2003;107:798-802.

82. Hiltunen JO, Laurikainen A, Airaksinen MS, Saarma M. GDNF family receptors in the embryonic and postnatal rat heart and reduced cholinergic innervation in mice hearts lacking ret or GFRalpha2. Dev Dyn. 2000;219:28-39.

83. Meixner A, Karreth F, Kenner L, Penninger JM, Wagner EF. Jun and JunDdependent functions in cell proliferation and stress response. Cell Death Differ. 2010;17:1409-19.

84. Wagner N, Wagner KD, Theres H, Englert C, Schedl A, Scholz H. Coronary vessel development requires activation of the TrkB neurotrophin receptor by the Wilms' tumor transcription factor Wt1. Genes Dev. 2005; 19:2631-42.

85. Werner P, Paluru P, Simpson AM, Latney B, lyer R, Brodeur GM, et al. Mutations in NTRK3 suggest a novel signaling pathway in human congenital heart disease. Hum Mutat. 2014;35:1459-68.

86. Lappas M. Lower circulating levels of complement split proteins C3a and C4a in maternal plasma of women with gestational diabetes mellitus. Diabet Med. 2011;28:906-11. 
87. Berrou J, Fougeray S, Venot M, Chardiny V, Gautier JF, Dulphy N, et al. Natural killer cell function, an important target for infection and tumor protection, is impaired in type 2 diabetes. PLoS ONE. 2013;8:e62418.

88. Ishizaki N, Okushi N, Yano T, Yamamura Y. Improvement in glucose tolerance as a result of enhanced insulin sensitivity during electroacupuncture in spontaneously diabetic Goto-Kakizaki rats. Metabolism. 2009:58:1372-8

89. lizuka $Y$, Ueda $Y$, Yagi Y, Sakurai E. Significant improvement of insulin resistance of GK rats by treatment with sodium selenate. Biol Trace Elem Res. 2010;138:265-71.

90. O'Rourke CM, Davis JA, Saltiel AR, Cornicelli JA. Metabolic effects of troglitazone in the Goto-Kakizaki rat, a non-obese and normolipidemic rodent model of non-insulin-dependent diabetes mellitus. Metabolism. 1997:46:192-8
91. Muniyappa R, Lee S, Chen H, Quon MJ. Current approaches for assessing insulin sensitivity and resistance in vivo: advantages, limitations, and appropriate usage. Am J Physiol Endocrinol Metab. 2008;294:E15-26.

92. Bell RM, Yellon DM. Conditioning the whole heart-not just the cardiomyocyte. J Mol Cell Cardiol. 2012;53:24-32.

93. Cury DP, Dias FJ, Sosthenes MC, Dos Santos Haemmerle CA, Ogawa K, et al. Morphometric, quantitative, and three-dimensional analysis of the heart muscle fibers of old rats: transmission electron microscopy and high-resolution scanning electron microscopy methods. Microsc Res Tech. 2013;76:184-95.

\section{Submit your next manuscript to BioMed Central and we will help you at every step:}

- We accept pre-submission inquiries

- Our selector tool helps you to find the most relevant journal

- We provide round the clock customer support

- Convenient online submission

- Thorough peer review

- Inclusion in PubMed and all major indexing services

- Maximum visibility for your research

Submit your manuscript at www.biomedcentral.com/submit 